\title{
COVID-19 drugs in aquatic systems: a review
}

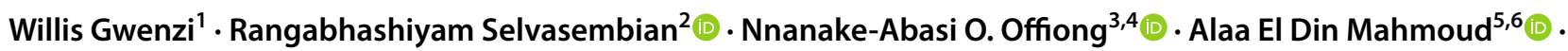 \\ Edmond Sanganyado ${ }^{7}$. Joyabrata $\mathrm{Mal}^{8}$
}

Received: 14 August 2021 / Accepted: 2 November 2021 / Published online: 15 January 2022

(C) The Author(s), under exclusive licence to Springer Nature Switzerland AG 2021

\begin{abstract}
The outbreak of the human coronavirus disease 2019 (COVID-19) has induced an unprecedented increase in the use of several old and repurposed therapeutic drugs such as veterinary medicines, e.g. ivermectin, nonsteroidal anti-inflammatory drugs, protein and peptide therapeutics, disease-modifying anti-rheumatic drugs and antimalarial drugs, antiretrovirals, analgesics, and supporting agents, e.g. azithromycin and corticosteroids. Excretion of drugs and their metabolites in stools and urine release these drugs into wastewater, and ultimately into surface waters and groundwater systems. Here, we review the sources, behaviour, environmental fate, risks, and remediation of those drugs. We discuss drug transformation in aquatic environments and in wastewater treatment systems. Degradation mechanisms and metabolite toxicity are poorly known. Potential risks include endocrine disruption, acute and chronic toxicity, disruption of ecosystem functions and trophic interactions in aquatic organisms, and the emergence of antimicrobial resistance.
\end{abstract}

Keywords Aquatic ecotoxicology $\cdot$ Behaviour $\cdot$ Fate processes $\cdot$ Health risks $\cdot$ Risk assessment

\section{Introduction}

(Re)-emerging viral zoonotic infections including severe acute respiratory syndrome coronavirus (SARS), H1N1 2009, H5N1 Influenza A, and Middle East respiratory

Willis Gwenzi

wgwenzi@yahoo.co.uk; wgwenzi@agric.uz.ac.zw

Rangabhashiyam Selvasembian

rambhashiyam@gmail.com

Nnanake-Abasi O. Offiong

no.offiong@topfaith.edu.ng

Alaa El Din Mahmoud

alaa-mahmoud@alexu.edu.eg

Edmond Sanganyado

esang001@ucr.edu

Joyabrata Mal

joyabrata@mnnit.ac.in

1 Biosystems and Environmental Engineering Research Group, Department of Agricultural and Biosystems Engineering, Faculty of Agriculture, Environment and Food Systems, University of Zimbabwe, P.O. Box MP 167, Mount Pleasant, Harare, Zimbabwe

2 Department of Biotechnology, School of Chemical and Biotechnology, SASTRA Deemed University, Thanjavur, Tamilnadu 613401, India syndrome (MERS) pose global public health risks (Zhong et al. 2003; Wang et al. 2013). Currently, the human coronavirus disease-2019 (COVID-19) caused by SARS-COV-2 is the most highly infectious disease causing significant global health concerns. As of October 2021, more than

3 International Centre for Energy and Environmental Sustainability Research (ICEESR), University of Uyo, Uyo, Nigeria

4 Department of Chemical Sciences, Faculty of Computing and Applied Sciences, Topfaith University, Mkpatak, Nigeria

5 Environmental Sciences Department, Faculty of Science, Alexandria University, Alexandria 21511, Egypt

6 Green Technology Group, Faculty of Science, Alexandria University, Alexandria 21511, Egypt

7 Guangdong Provincial Key Laboratory of Marine Biotechnology, Institute of Marine Science, Shantou University, Shantou 515063, China

8 Department of Biotechnology, Motilal Nehru National Institute of Technology Allahabad, Prayagraj, Uttar Pradesh, India 
230 million confirmed cases and almost 4.8 million deaths have been reported globally, with countries in the Americas and Europe being the worst affected (Fig. 1) (Muhammad et al. 2020; WHO 2021a, b). Several pharmaceuticals such as antibiotics, antiretroviral drugs, and antimalarial drugs have been repurposed for treating COVID-19, although the efficacy of some remains contended (Kuroda et al. 2021). In addition, several old drugs such as nonsteroidal antiinflammatory drugs and analgesics are widely used to treat COVID-19 related symptoms such as fever, acute pain, and inflammation (Galani et al. 2021). Hence, global consumption of pharmaceuticals has probably increased during the
Fig. 1 Number of cumulative total of COVID-19 cases (a) and deaths (b) reported up to 27 February, 2021 (WHO 2021b)
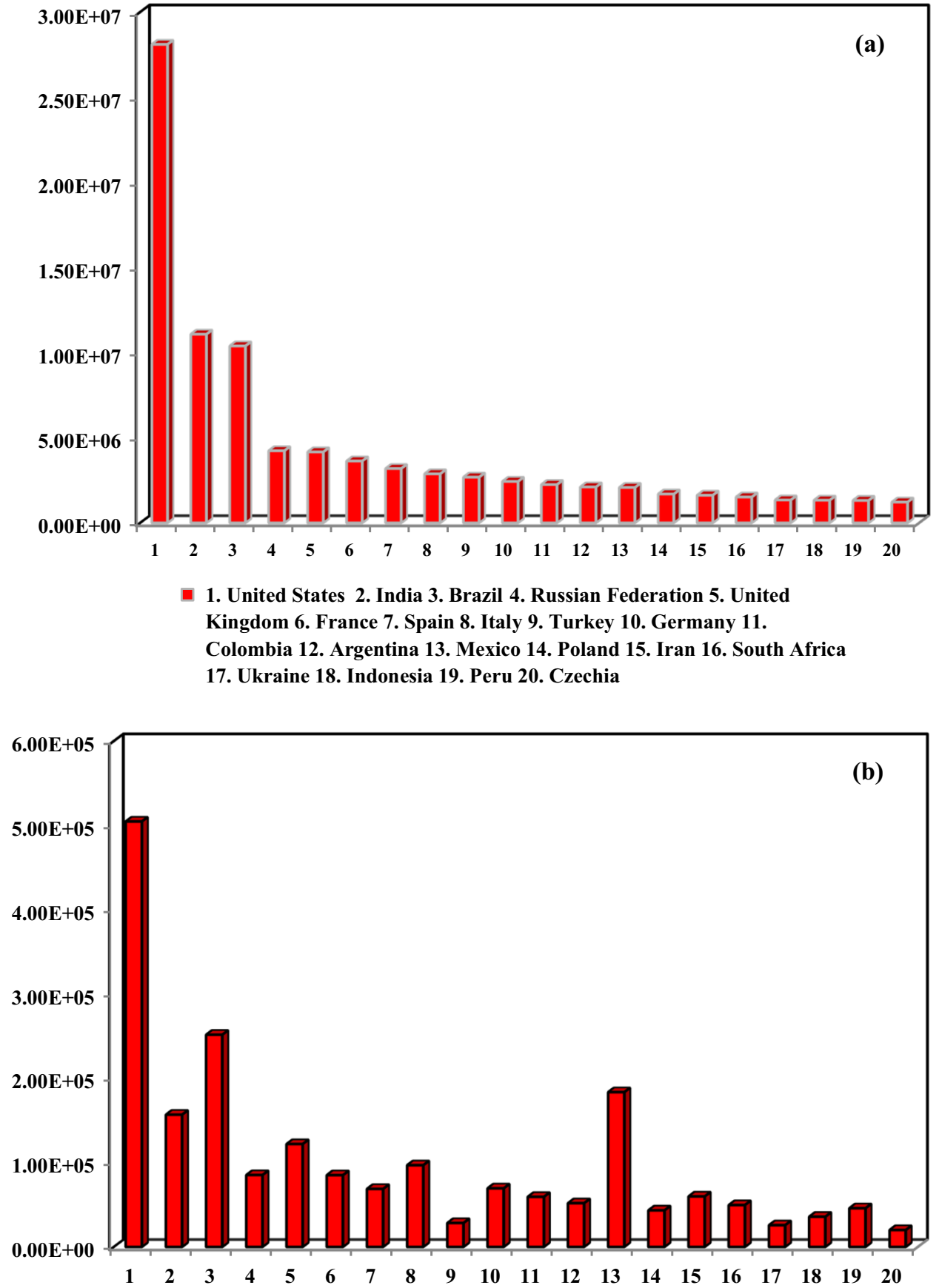

$\square$ 1. United States 2. India 3. Brazil 4. Russian Federation 5. United Kingdom 6. France 7. Spain 8. Italy 9. Turkey 10. Germany 11. Colombia 12. Argentina 13. Mexico 14. Poland 15. Iran 16. South Africa 17. Ukraine 18. Indonesia 19. Peru 20. Czechia 
COVID-19 pandemic and will continue to do so with the advent of highly transmissible variants. For example, there was a $179-1977 \%$ increase in prescriptions and refills for hydroxychloroquine and chloroquine in the US in 2020 (Vaduganathan et al. 2020). The presence of COVID-19 related pharmaceuticals such as antibiotics (Jan et al. 2016; Ahmed et al. 2020), antiviral drugs (Kuroda et al. 2021), and nonsteroidal anti-inflammatory drugs (Wang et al. 2021a, b) in aquatic environments may contribute to the emergence of antimicrobial resistant pathogens, which will further complicate the management of COVID-19.

There are currently no comprehensive reviews on the sources, environmental fate, and health risks of COVID19 related pharmaceuticals and their metabolites in aquatic environments, as most reviews focused on pharmacology (Wu et al. 2020b; Hussain et al. 2020; Matera et al. 2020), wastewater treatment (Revilla Pacheco et al. 2021), and hazard assessment (Biswas et al. 2021; Kumari and Kumar 2021; Kuroda et al. 2021; Abhishek et al. 2021; Khan et al. 2021; Abhinandan et al. 2021). Therefore, in this review, we examine the impact of COVID-19 related pharmaceuticals using the source-pathway-recepetor-impact-mitigation continuum. We first consider the hypotheses that COVID19 pandemic increased the emission of COVID-19 related pharmaceuticals into aquatic environments resulting in an increase in human and ecological risks by critically examining previous environmental monitoring and characterization studies. We also explored the chemodynamics of COVID-19 related pharmaceuticals in wastewater treatment plants and natural aquatic environments with the goal of highlighting principal mitigation strategies, and future directions. Figure $2 \mathrm{a}$ indicates the number of research documents published by different countries based on the data collected up to 28 February 2021 (SCOPUS with the keyword search for COVID-19) considering the top 20 countries. Fig. $2 b$ illustrates the research documents published by different countries by keywords searching for (a) COVID-19 and (b) COVID-19 + Therapeutic Drugs from SCOPUS 2021 database based on data considered up to 28 February, 2021 with the top 20 countries. The data in Fig. 2 reveal that the research document publications related to COVID-19 and therapeutic drugs show similar trends. The observed few countries occupying the first 20 positions in the therapeutic drugs keywords search in SCOPUS signifies that different countries have varying research interests towards the therapeutic drugs related to COVID-19. The COVID-19 related documents output from worldwide were one or two up to 2018, followed by 42 documents in 2019 and sudden increase up to 84,277 documents published in 2020 . Also, no documents reported therapeutic drugs related to COVID-19 up to 2019, but in 2020 and by 28 February, 2021 the reported number of documents were 2042 and 366, respectively (Fig. 2c). These data point out the awareness and scientific interest or priority among the different research groups on COVID-19 and the associated search for the therapeutic drugs for the COVID-19 treatment.

\section{Consumption patterns of COVID-19 related pharmaceuticals}

The COVID-19 related pharmaceuticals consumed globally are often experimental, unapproved, or approved treatments. As of October 2021, more than 700 and 1000 potential drug interventions for treating COVID-19 were listed in the Drug Bank (https://go.drugbank.com/covid-19) and the US Clinical Trials registry (https://clinicaltrials.gov/ct2/resul ts?cond=COVID-19), respectively. The COVID-19 related pharmaceuticals in these registries included analgesic (e.g. acetaminophen, tramadol), antibiotics (e.g. azithromycin, clarithromycin, and clofazimine), anticancer drugs (e.g. antroquinonol, ruxolitinib, and tamoxifen), antidepressants (e.g. fluoxetine and fluvoxamine), antimalarials (artemether, chloroquine, and hydroxychloroquine), nonsteroidal anti-inflammatory drugs (e.g. acetylsalicylic acid, dexamethasone, and ibuprofen), antivirals (e.g. ribavirin, and oseltamivir), and antiretroviral drugs (e.g. azvudine, lopinavir, and tenofovir), and veterinary antiparasitic drugs (e.g., ivermectin). Most analgesics and nonsteroidal anti-inflammatory drugs used to treat COVID-19 symptoms such as fever are overthe-counter drugs; thus, they are predominantly consumed in residential areas. Although the remaining COVID-19 related pharmaceuticals classes are mainly administered in hospitals or at home with prescription, antibiotics, antivirals, and antiretrovirals are often obtained over-the-counter or illegally in developing countries (Gwenzi and Chaukura 2018; Sanganyado 2019). Additionally, the spread of misinformation has contributed to an increase in self-medication and misuse of veterinary medicines (i.e. ivermectin) and antimalarial drugs (i.e. chloroquine and hydroxychloroquine) (Fittler et al. 2021; Love et al. 2020). In Togo, $34.2 \%$ of survey participants $(n=955)$ reported that they self-medicated after experiencing COVID-19-like symptoms with $2.0 \%$ using chloroquine and hydroxychloroquine (Sadio et al. 2021). In Greece, there was a significant decrease in the consumption of antihypertensive, diuretic, and antilipidemic drugs during lockdown (Galani et al. 2021). Hence, the strict lockdowns enacted by various countries across the globe may have decreased access to medical facilities such as clinics, hospitals, and pharmacies to non-COVID-19 patients, which could result in a decrease in consumption of non-COVID-19 related pharmaceuticals (Galani et al. 2021; Oikonomou et al. 2020). Additionally, the COVID-19 pandemic has contributed to the disruption of the supply chain of generic drugs sourced from countries with strict lockdown procedures and shift in consumption of branded drugs 
Fig. 2 Number of documents published by countries for (a) COVID-19 and (b) COVID-

$19+$ therapeutic drugs, and

(c) by year up to 28 February, 2021
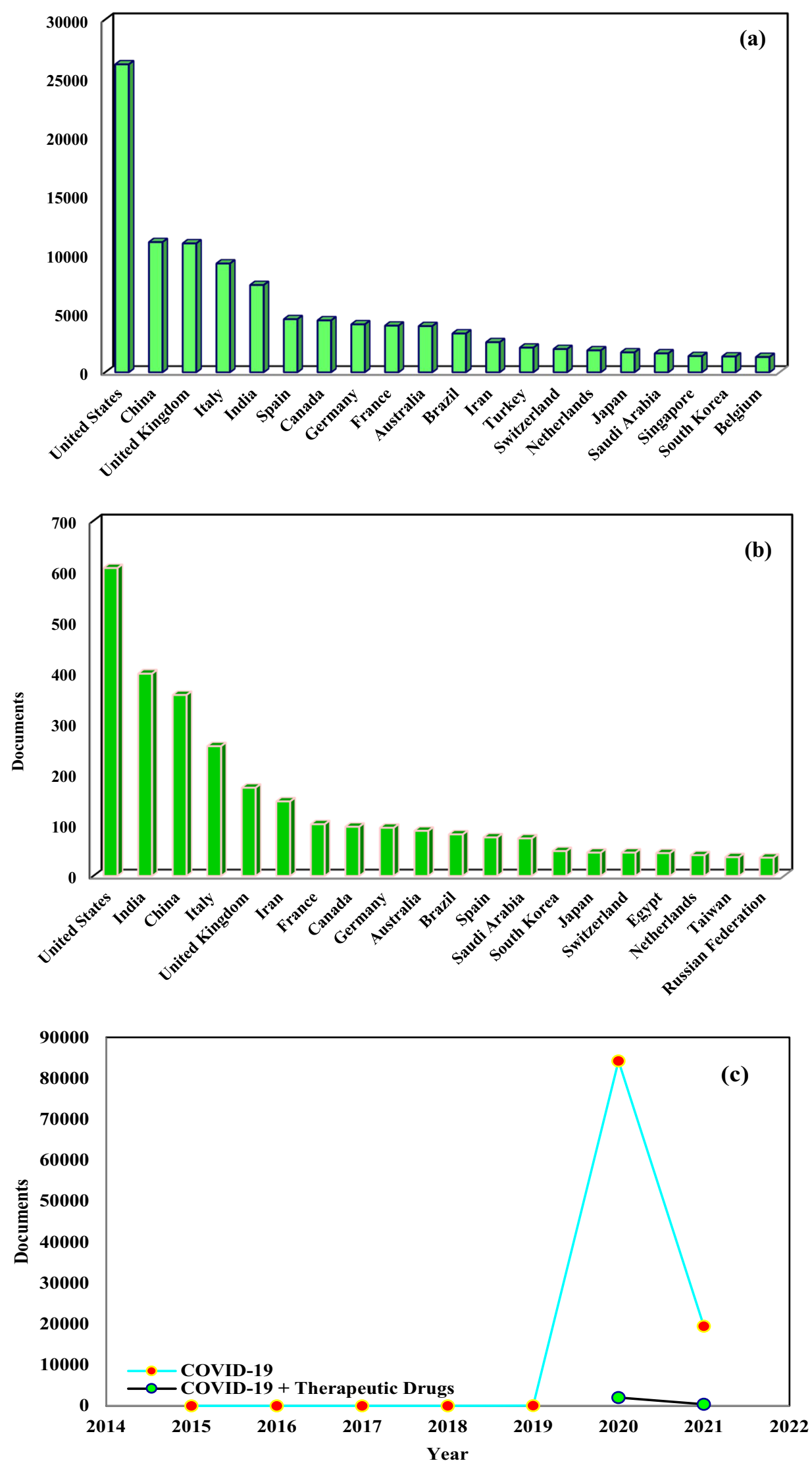
towards COVID-19 drugs leaving non-COVID-19 patients untreated ( https://cen.acs.org/business/outsourcing/COVID19-reshaping-pharmaceutical-supply/98/i16). While vaccine use is expected to decrease the number of COVID-19 cases, the potential advent of highly transmissible variantss compounded by the lack of access to the vaccines among developing countries and increasing vaccine hesitancy suggest COVID-19 related pharmaceuticals consumption will continue to increase worldwide (Burki 2021).

\section{COVID-19 drugs in aquatic systems}

\section{Sources and dissemination}

The emergence and prevalence of COVID-19, and the accompanying surge in the production and use of therapeutic drugs lead to an increase in the concentration and spectrum of COVID-19 drugs in aquatic systems. Potential sources of drugs and their metabolites include solid wastes, wastewaters and effluents from pharmaceutical industries (Mahmoud 2020a). Wastewater effluents from healthcare facilities such as hospitals and clinics often contain high concentrations of drugs and their metabolites (Vambol et al. 2021), and these are expected to increase during COVID19 pandemic (Mousazadeh et al. 2021). Solid wastes and wastewaters from COVID-19 quarantine centres, and even households of symptomatic and asymptomatic COVID19 patients may contain elevated concentrations of drugs and their metabolites (Espejo et al. 2020). The COVID-19 induced increase in drug and metabolites adds to the existing pharmaceutical burden associated with other human co-morbidities.

A significant portion of the parent drugs administered to treat human infections including COVID-19, and their metabolites are excreted via urine and faeces into municipal wastewater and on-site sanitation systems. For example, about $30-90 \%$ of pharmaceuticals are not metabolized, and their residuals end up in wastewater treatment plants (O'Flynn et al. 2021). Depending on the removal efficiency of the wastewater treatment process applied, a fraction of the drugs and their metabolites are released in effluents from wastewater treatment plants. Drugs and their metabolites in wastewater effluents are then eventually released into surface water and groundwater systems via run-off, direct discharge, accidental spillages, infiltration, recharge, and surface watergroundwater interactions (Gwenzi and Chaukura 2018). For instance, various pharmaceutical drugs such as antibiotics were detected up to $\mathrm{mg} \mathrm{L}^{-1}$ in groundwater in Germany (aus der Beek et al. 2016). However, the concentrations detected in groundwater systems depend on several factors including attenuation in the overlying soils. It is possible that COVID-19 drugs cannot reach groundwater wells if the vadose zone is thick (i.e. $30-40 \mathrm{~m}$ ) because the infiltration of contaminated effluents is often slow and takes long time (Elkayam et al. 2018). Hence, municipal wastewater is one of the main end routes of these pharmaceuticals and their metabolites, which are then disseminated into aquatic systems. Besides surface water and groundwater pollution, several practices may also contribute to the dissemination of COVID-19 drugs and their metabolites. This includes the use of raw or treated wastewater in irrigation, recreation, and groundwater recharge. Human exposure to COVID-19 drugs and their metabolites may also occur via oral ingestion of contaminated groundwater. The risk of aquatic pollution by COVID-19 drugs and their metabolites are particularly high in low-income countries. This is because they rely on conventional wastewater treatments systems based on primary and secondary treatment processes without advanced treatment options such as tertiary treatment (Gwenzi and Sanganyao, 2019; Mahmoud et al. 2020; Mahmoud 2020b). Low-income countries also lack effective policies and regulatory frameworks to minimize aquatic pollution.

To date, comprehensive studies on the occurrence and dissemination of COVID-19 drugs and their metabolites in the pharmaceutical value-chain are still lacking. O'Flynn et al. (2021) highlighted the life cycle assessment (LCA) of pharmaceuticals from production to release into the aquatic environment. The merits of having such LCA is that it can track the route of pharmaceuticals into the environment as well as follow the sustainable development targets of SDG 6 (Clean Water and Sanitation), SDG 12 (Responsible Consumption and Production), and SDG 14 (Life Below water). LCA can be used to identify dominant pollution hotspots along the pharmaceutical value-chain, and inform the targeting of mitigation measures including wastewater treatment.

Despite several studies published on COVID-19 starting from 2019 (Fig. 2), globally, there is a lack of data investigating the occurrence, behaviour, fate and ecological health risks of COVID-19 therapeutic drugs in aquatic systems, and other environmental compartments. In the absence of comprehensive data based on direct monitoring, wastewater-based epidemiology (WBE) is a promising approach to monitor COVID-19 drugs in the wastewater at a community level (Kumar et al. 2020a, b; Reinstadler et al. 2021). WBE can be used as an early warning tool for the potential spread of various types of COVID-19 drugs and their metabolites. WBE has been successfully used for the monitoring of SARS-CoV-2, and several pharmaceuticals in aquatic systems (Ahmed et al. 2020). A closer examination of the literature retrieved using the search term (COVID-19+drugs) gave papers mainly focussing on the therapeutic effects of such drugs. Only a few exceptions exist, and these are summarized in the subsequent section. 


\section{Early results}

The few studies available on COVID-19 drugs and their metabolites are based three lines of evidences: (1) direct measurement in aquatic systems (Tarazona et al. 2021), (2) predictions based on global use and excretion rates (Kuroda et al. 2021), and (3) inferential evidence related to the pre-COVID-19 outbreak period on the occurrence, behaviour and fate of old and repurposed COVID-19 drugs.

One study predicted the environmental concentrations (PEC) in influent wastewater, secondary effluent, and downstream river water (Kuroda et al. 2021). The study used Eqs. (1)-(3) based on the number of COVID-19 patients, daily dosage of a specific drug, fraction excreted via urine and faeces, water consumption per capita, and removal efficiency in wastewater treatment plants (Ghosh et al. 2010; Keller et al. 2014). The various PEC values were estimated from daily drug dose $\left(D_{\mathrm{d}}\right)$, fraction of pharmaceutical excreted by humans following administration $(f)$, number of people taking the pharmaceutical per population of 100,000 $\left(N_{\mathrm{t}}\right)$, wastewater generated per inhabitant $\left(W_{\mathrm{c}}\right)$, and wastewater removal efficiency $(R)$.

$$
\begin{aligned}
& \mathrm{PEC}_{\text {influent }}=\frac{N_{\mathrm{t}}}{100,000} \times \frac{D_{\mathrm{d}} \times f \times 10^{6}}{W_{\mathrm{c}}} \\
& \mathrm{PEC}_{\text {secondary effluent }}=\mathrm{PEC}_{\text {influent }} \times(1-R) \\
& \mathrm{PEC}_{\text {river }}=\frac{\mathrm{PEC}_{\text {secondary effluent }}}{10}
\end{aligned}
$$

The study predicted concentrations of the 11 therapeutic drugs in the raw wastewater, secondary effluent, and river water. However, besides antibiotic resistance, the work by Kuroda et al. (2021) excluded the following factors: (1) The potential ecotoxicity and selection pressure exerted by degradation products of drugs; (2) potential interactive effects of the drugs with other environmental stressors including legacy pharmaceuticals and other emerging contaminants; and (3) other ecotoxicological health risks such as genotoxicity, reproductive toxicity, and impacts on trophic interactions. Chloroquine, hydroxychloroquine, lopinavir, ribavirin, teicoplanin, and umifenovir occurred in higher concentrations $(>800 \mathrm{ng} / \mathrm{L})$ in raw wastewater than the other five drugs. Significant removal (63-95\%) of chloroquine, lopinavir, ritonavir, and umifenovir occurred via wastewater treatment, resulting in lower concentrations in the secondary effluent. However, wastewater treatment had no or limited effect on the removal $(<3 \%)$ of the other seven drugs. Intuitively, chloroquine, hydroxychloroquine, ribavirin, and teicoplanin, which had high initial concentrations in wastewater as well as low removal had the highest concentrations in river water. These data provide some indicative estimates of the concentrations of COVID-19 drugs released into the various aquatic systems. However, there is need to be cautious when interpreting the data because several factors controlling the concentrations of the drugs were not addressed. For example, removal efficiencies may vary considerably among wastewater treatment processes. The data on degradation and fate processes were drawn from predominantly temperate regions in developed countries, while the corresponding data from tropical climates in low-income countries are unavailable. As evident in Eq. (3), the reduction in concentration due to degradation and fate processes were not considered. Thus, scope exists to improve the estimates using data drawn at national, regional or continental levels.

A study conducted in Spain showed that the concentrations of hydroxychloroquine in wastewater $(0.11 \mathrm{mg} / \mathrm{L})$ were higher or lower than that in the downstream river water (0.013-0.42 mg/L). The lower concentrations in downstream river water than in wastewater could be attributed to the photodegradation of hydroxychloroquine in aquatic environments (Kumar et al. 2021). The photodegradation of hydroxychloroquine in aquatic environment has been reported in the literature, and is $\mathrm{pH}$-dependent, being higher under alkaline than acidic pH condition (Dabić et al. 2019; Kumar et al. 2021). On the other hand, the higher concentrations in river water than wastewater point to other pollution sources of hydroxychloroquine in the catchment.

Notably, several of the COVID-19 drugs and their metabolites were detected in aquatic environments even before the outbreak of COVID-19 (Chițescu and Nicolau 2014; Schwientek et al. 2016). These include nonsteroidal antiinflammatory drugs such as diclofenac, antibiotics such as ciprofloxacin, and antivirals used to treat other infections (Chițescu and Nicolau 2014; Schwientek et al. 2016). Several papers including reviews exist on the occurrence of some of the old and repurposed drugs currently used to treat COVID-19 (aus der Beek et al. 2016; Gwenzi and Chaukura 2018). Therefore, one expects that the outbreak of COVID19 may increase the concentrations and spectrum of pharmaceuticals in aquatic systems. However, currently missing are comparative studies investigating the nature and concentrations of COVID-19 therapeutic drugs in the pre-and post-COVID-19 outbreak periods. Such data are crucial in determining the magnitude of change in terms of concentration and spectrum of drugs since the outbreak of COVID-19. Thus, the limited studies available coupled with lack of comparative studies highlight the need for further research on the occurrence of COVID-19 drugs in aquatic environments. 


\section{Behaviour and fate in aquatic systems}

A number of old and repurposed drugs for treatment of COVID-19 or those used for trial studies have been previously investigated in terms of their environmental fate in aqueous matrices. These classes of therapeutics include those used as supporting agents, e.g. ibuprofen, indomethacin, naproxen, ascorbic acid, and antimalarial, antiparasitics and /antiviral drugs (e.g. chloroquine, hydroxychloroquine, ivermectin, amodiaquine) (Bocci et al. 2020; Drożdżal et al. 2020; McKee et al. 2020; Wu et al. 2020a). In comparison to these classes of therapeutics, newly developed and a significant number of repurposed drugs are sparingly studied or are without data at all. Some novel drugs targeting COVID19 have been reviewed (Sternberg et al. 2020).

The conditions of the receiving environmental are important factors that control the fate of drugs in aquatic environments. Other processes that control the environmental fate of pharmaceutically active compounds in aquatic environments are aqueous solubility, bioaccumulation, biotransformation, photolysis, and sorption to sediments as well as biofilms (Hanamoto and Ogawa 2019; Li et al. 2015). These processes are in turn determined by the chemical structures and other physicochemical parameters of the drugs including aqueous solubility, octanol-water partition coefficient (log $K_{\text {ow }}$ ), and acid dissociation constant (pKa). These parameters are summarized in Table 2 for selected therapeutic drugs used orf repurposed for COVID-19.

Generally, positive $\log K_{\text {ow }}$ and low aqueous solubility reveals the tendency of bioaccumulation and preferential partition to organic phase such as soils and sediments. On the other hand, low pKa values implies stronger acid and vice versa. For instance, the antiparasitic agent ivermectin $\left(\log K_{\mathrm{ow}}=4.61\right.$, with very low aqueous solubility) has been identified as a candidate for COVID-19 treatment (Essid et al. 2020). However, once in the environment ivermectin is expected to be persistent (Löffler et al. 2005). In fact, a half-life of more that 100 days in marine sediments has been reported (Essid et al. 2020). Under natural attenuation conditions of a water/sediment system, it has been reported that only about $31 \%$ of initially applied ivermectin was transformed (Prasse et al. 2009) (Table 1).

With promising potential in clinical trials, hydroxychloroquine and chloroquine are among the spotlighted repurposed drugs under current investigation for treating COVID19 (Satarker et al. 2020). Although the hydroxyl group on hydroxychloroquine makes it less toxic than chloroquine, both share similar activity and reactivity (Wu et al. 2020a). Nevertheless, the hydroxyl group imparts greater aqueous solubility on hydroxychloroquine than chloroquine (Table 2) (Schroeder and Gerber 2014). With moderate octanol-water partition coefficients (3.0-4.5, Table 2), both chloroquine and hydroxychloroquine may accumulate in organic phases over time and display some level of persistence in natural waters and conventional treatment plants.

Treatment of pharmaceutically active compounds in conventional wastewater treatment plants has always been marred by poor removal rates because such treatment plants were not originally designed to remove such contaminants. This challenge is expected to be more complicated during a pandemic when such drugs are heavily administered with significant amounts excreted unmetabolized (Bartels and von Tümpling 2008). In the case of oseltamivir which was used during the influenza pandemic of 2009 and has been repurposed for COVID-19, previous environmental evaluations had revealed widespread occurrence and a slow degradation rate (Drożdżal et al. 2020; Ghosh et al. 2010; Wu et al. 2020a). Oseltamivir, an antiviral drug, has moderate solubility in water (Table 2) but is very difficult to remove. Under normal treatment conditions in wastewater treatment plants, it has been reported that oseltamivir was not degraded or removed (Fick et al. 2007). It has been concluded that direct photolysis of oseltamivir via daylight exposure plays no or only negligible role in the degradation of oseltamivir (Bartels and von Tümpling 2008) (Table 1). However, oseltamivir was said to respond effectively to microbial metabolism or indirect photolysis (Bartels and von Tümpling 2008). In cases such as this, it is expected that newly developed treatment options suitable for scenario-specific contamination may be necessary. For example, photocatalysis of oseltamivir using UV-C and $\mathrm{TiO}_{2}$ proved effective with about $98 \%$ removal rate. However, the relatively new electrocoagulation method developed for removal of the anti-inflammatory drug dexamethasone only gave $38.1 \%$ removal rate (Arsand et al. 2013). Dexamethasone is among the US Food and Drug Administration (US FDA) approved drugs with pharmacotherapeutic potential for COVID-19 (Drożdżal et al. 2020). With positive $\log K_{\text {ow }}$ and moderate aqueous solubility, the relatively new antiviral drug remdesivir is expected to display some persistence in aquatic environment as well as sorb to organic phases. In spite of being among the leading candidates as a repurposed drug for COVID-19 (El-Din Abuo-Rahma et al. 2020; Nittari et al. 2020), remdesivir is yet to receive broader scrutiny in terms of environmental fate.

As can be observed in Table 1, many of the highlighted drugs were studied in simulated conditions and natural attenuation process or present conventional methods were mostly ineffective for the treatment or removal. Data on their occurrence and fate in surface run-off, dumpsite leachates, groundwater, and storm water, which are important for lowincome countries where wastewater treatment plants are often not used or are inefficient are sparse or non-existent (Offiong et al. 2019). 


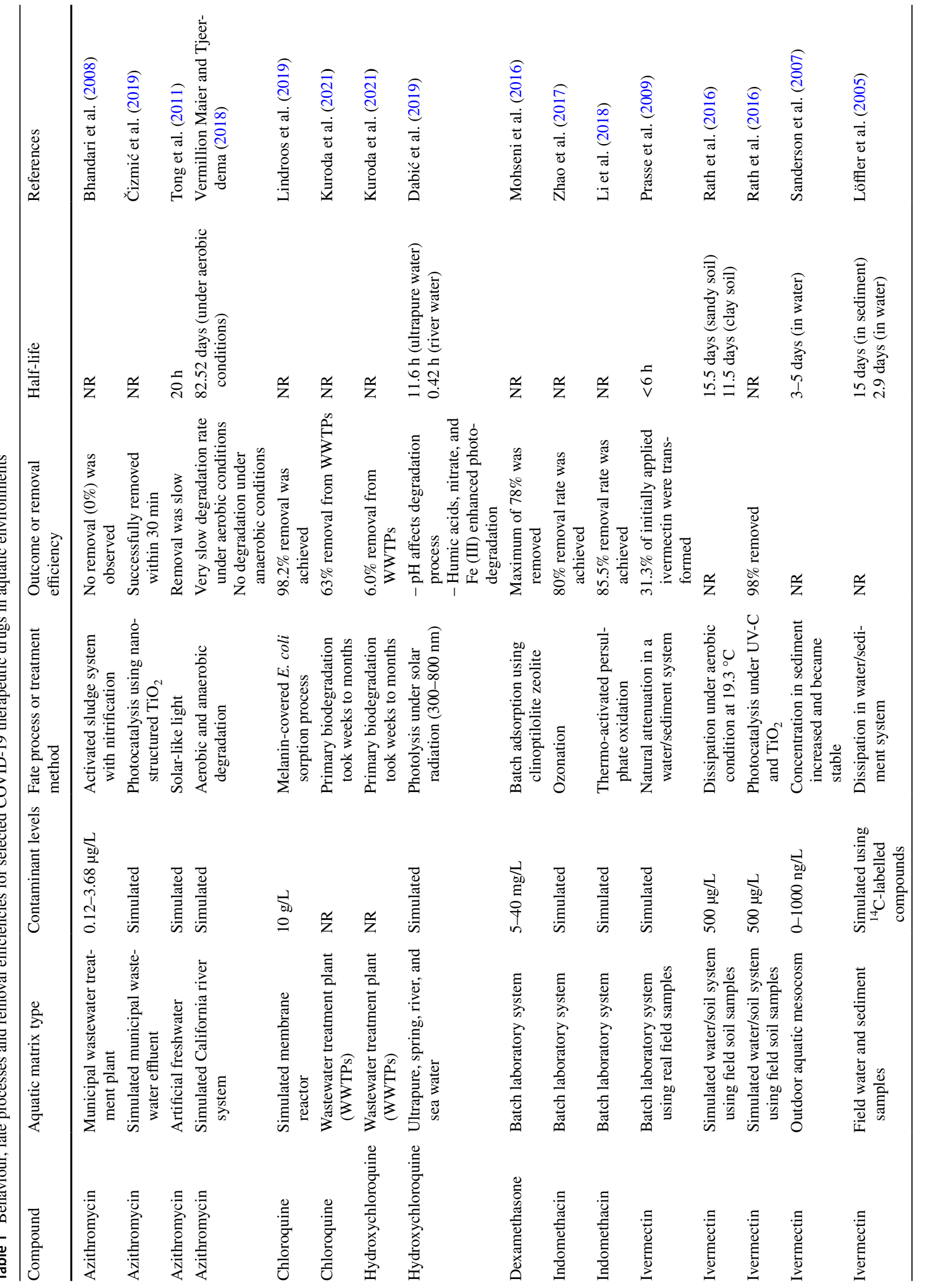




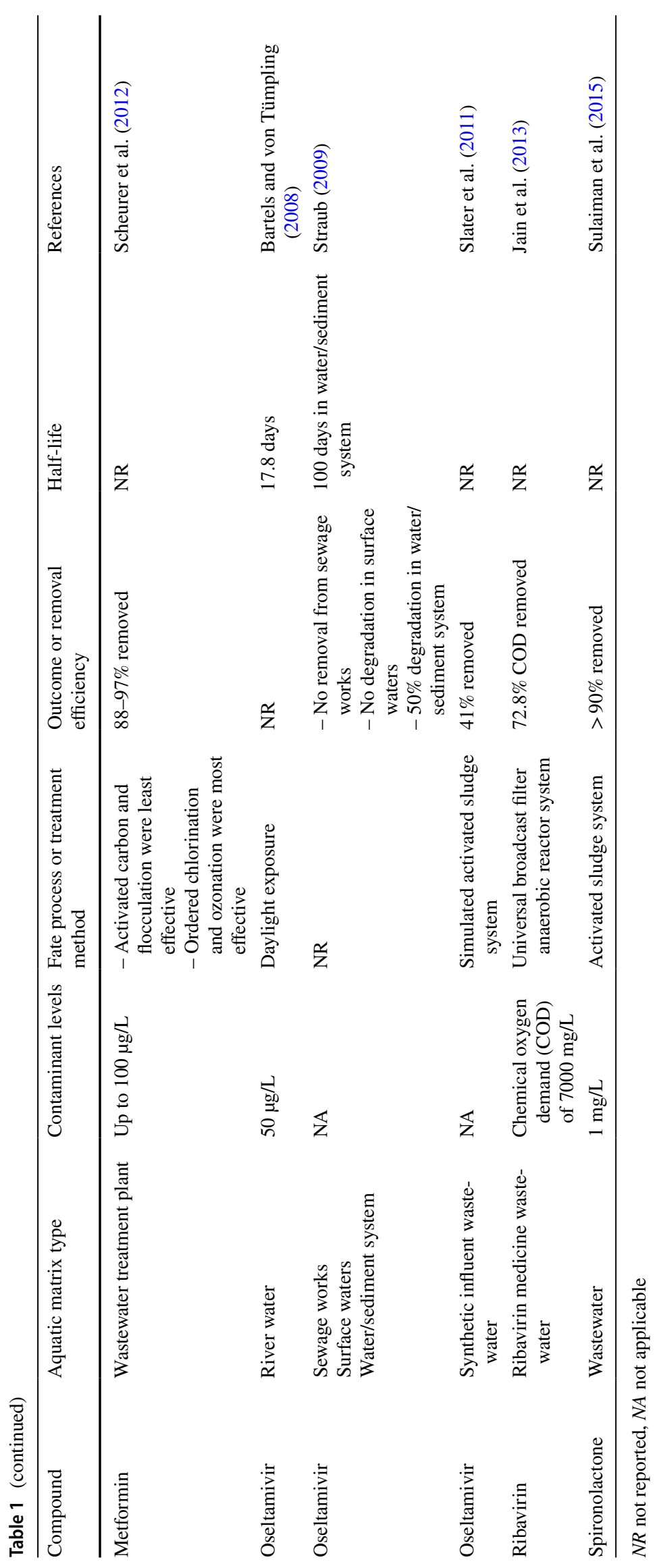


Table 2 Aqueous solubility, acid dissociation constants, and octanol-water partition coefficients of selected drugs used or repurposed for COVID-19 treatment

\begin{tabular}{|c|c|c|c|c|c|c|}
\hline Compound & M.F. & M.W. (g/mol) & $\begin{array}{l}\text { Aqueous solubil- } \\
\text { ity at } 25^{\circ} \mathrm{C} \\
(\mathrm{mg} / \mathrm{L})\end{array}$ & $\mathrm{pKa}$ & $\log K_{\text {ow }}$ & References \\
\hline Azithromycin & $\mathrm{C}_{38} \mathrm{H}_{72} \mathrm{~N}_{2} \mathrm{O}_{12}$ & 749.12 & 5430.0 & $9.45(8.74)$ & 4.02 & $\begin{array}{l}\text { Hanamoto and Ogawa (2019) and McFar- } \\
\text { land et al. (1997) }\end{array}$ \\
\hline Chloroquine & $\mathrm{C}_{18} \mathrm{H}_{26} \mathrm{ClN}_{3}$ & 319.90 & 7000.0 & $10.47(6.33)$ & 4.67 & Rendal et al. (2011) \\
\hline Hydroxychloroquine & $\mathrm{C}_{18} \mathrm{H}_{26} \mathrm{ClN}_{3} \mathrm{O}$ & 335.9 & 86,000 & $9.7(8.3)$ & 3.0 & $\begin{array}{l}\text { Dabić et al. (2019), Fick et al. (2010) and } \\
\text { Schroeder and Gerber (2014) }\end{array}$ \\
\hline Ivermectin & $\mathrm{C}_{48} \mathrm{H}_{74} \mathrm{O}_{14}$ & 875.12 & 0.0002715 & Neutral & 4.61 & Escher et al. (2008) and Ryu et al. (2018) \\
\hline Lopinavir & $\mathrm{C}_{37} \mathrm{H}_{48} \mathrm{~N}_{4} \mathrm{O}_{5}$ & 628.81 & 0.0000077 & 13.39 & 5.94 & Ncube et al. (2018) \\
\hline Metformin & $\mathrm{C}_{4} \mathrm{H}_{11} \mathrm{~N}_{5}$ & 129.16 & $300,000.0$ & $12.3(1.03)$ & -0.92 & $\begin{array}{l}\text { Briones et al. (2016), Guibal et al. (2020) } \\
\text { and Scheurer et al. (2009) }\end{array}$ \\
\hline Oseltamivir carboxylate & $\mathrm{C}_{14} \mathrm{H}_{24} \mathrm{~N}_{2} \mathrm{O}_{4}$ & 284.35 & $>500.0$ & $3.6(8.9)$ & -0.006 & Straub (2009) \\
\hline Oseltamivir ethylester & $\mathrm{C}_{16} \mathrm{H}_{28} \mathrm{~N}_{2} \mathrm{O}_{4}$ & 312.41 & $>200.0$ & $3.6(8.2)$ & -1.21 & Straub (2009) \\
\hline Penciclovir & $\mathrm{C}_{10} \mathrm{H}_{15} \mathrm{~N}_{5} \mathrm{O}_{3}$ & 253.26 & 1700.0 & $3.2(9.4)$ & -2.1 & $\begin{array}{l}\text { Morgan et al. (2003) and Prasse et al. } \\
\text { (2010) }\end{array}$ \\
\hline Ribavirin & $\mathrm{C}_{8} \mathrm{H}_{12} \mathrm{~N}_{4} \mathrm{O}_{5}$ & 244.2 & $142,000.0$ & $5.9\left(-\mathrm{NH}^{+}\right)$ & -1.85 & $\begin{array}{l}\text { Goodarzi et al. (2016) and Prasse et al. } \\
\text { (2010) }\end{array}$ \\
\hline Ritonavir & $\mathrm{C}_{37} \mathrm{H}_{48} \mathrm{~N}_{6} \mathrm{O}_{5} \mathrm{~S}_{2}$ & 720.21 & 0.00000011 & 13.68 & 6.27 & Ncube et al. (2018) \\
\hline Remdesivir & $\mathrm{C}_{27} \mathrm{H}_{35} \mathrm{~N}_{6} \mathrm{O}_{8} \mathrm{P}$ & 602.6 & 339.0 & 10.23 & $2.0-2.2$ & Hanafin et al. (2020) \\
\hline
\end{tabular}

pKa values in bracket represent those of a second proton

M.F. molecular formula, M.W. molecular weight

Studies on the photodegradation and other transformation products of pharmaceutically active compounds are important to elucidate their fate in environmental matrices (Boreen et al. 2003; Li et al. 2015). Understanding of chemical fate and transport in environmental matrices is essential for their control and management. With almost half of administered chloroquine and hydroxychloroquine excreted back to the environment and with a moderate persistence of up to several months (Kuroda et al. 2021), there are concerns that predicted no-effect concentrations would be exceeded during periods of widespread administration such as the COVID-19 pandemic. In the environment, photolysis of hydroxychloroquine could result in hydrolysis of the quinoline moiety. Complete mineralization could be achieved via degradation by electrogenerated oxidants using boron-doped diamond (BDD) anodes (Bensalah et al. 2020). In the case of chloroquine, dealkylation mechanism during photolysis has been reported (Ahmad et al. 2016; Patel et al. 2019). Photo-oxidation to quinoline derivatives of smaller molecular weights containing amines and ether groups have been reported (Nord et al. 1991). All these sums up to the possibility of achieving $80 \%$ removal efficiency predicted for (hydroxy)chloroquine in WWTPs (Kuroda et al. 2021).

Although, oseltamivir is administered orally as a phosphate salt, its conjugated acid, oseltamivir ethylester (OE) is converted in the liver by esterases to the oseltamivir acid
(OA), the active metabolite that is excreted almost $80 \%$ via urine (Ghosh et al. 2010). This metabolite was detected at high concentration in wastewater samples during the influenza pandemic (Mestankova et al. 2012). Therefore, transformation products (TPs) could be indicators for monitoring the extent of use of parent pharmaceuticals (PPs) during pandemics. Sometimes, the TPs are more, if not equally toxic as the parent compounds (Li et al. 2015). However, degradation is usually assumed to lead to less toxic or completely benign by-products.

\section{Ecotoxicology}

Therapeutic drugs used to treat COVID-19 and related human health conditions include: (1) anti-parasitics (e.g. ivermectin and niclosamide), anti-malarials and DMARDs (e.g. chloroquine, and hydroxychloroquine), and antivirals and antiretrovirals (e.g. remdesivir, lopinavir, ritonavir, favipiravir, ribavirin, oseltamivir, and umifenovir) (Jeana and Hsueh 2020; Wu et al. 2020a). Note that, in addition to those highlighted here, the number of therapeutics currently used for COVID-19 and related human health conditions is quite broad. These include nonsteroidal anti-inflammatoyr drugs (NSAIDs), analgesics, chemoprotective or supporting agents, and the recently developed vaccines (Wu et al. 2020a; WHO 2021a, b). Therefore, 
Table 3 Ecotoxicology of some of the COVID-19 therapeutic drugs reported in literature

\begin{tabular}{|c|c|c|}
\hline Drug & Ecotoxicological effects and remarks & References \\
\hline Chloroquine & $\begin{array}{l}\text { 24-h exposure } \mathrm{EC}_{50} \text { for the inhibition of bioluminescence in bacteria (Aliivibrio fischeri) } \\
\text { was } 132.1 \mathrm{mg} / \mathrm{L}\end{array}$ & Zurita et al. (2005) \\
\hline Hydroxychloroquine & $\begin{array}{l}\text { For algae (Raphidocelis subcapitata) the EC50 for the inhibition of growth rate after a } \\
\text { 72-h exposure was } 3.1 \mathrm{mg} / \mathrm{L}\end{array}$ & FASS (2019) \\
\hline Ivermectin & $\begin{array}{l}\text { The EC50 in Daphnia magna was } 25 \mathrm{ng} / \mathrm{L} \text {, while the predicted NOEC for an invertebrate } \\
\text { was about } 10 \mathrm{ng} / \mathrm{L}\end{array}$ & Montforts et al. (2003) \\
\hline Niclosamide & 12-h exposure $\mathrm{EC}_{50}$ for rainbow trout (Oncorhynchus mykiss) was of $0.11 \mathrm{mg} / \mathrm{L}$ & Hepditch et al. (2021) \\
\hline Lopinavir & $\begin{array}{l}\text { Predicted NOEC for algae was } 0.05 \mu \mathrm{g} / \mathrm{L} \text { which was below predicted effluent concentra- } \\
\text { tion }(0.26 \mu \mathrm{g} / \mathrm{L})\end{array}$ & Acree Jr et al. (2012) \\
\hline Ritonavir & The measured NOEC for green algae was less than $1.59 \mathrm{mg} / \mathrm{L}$ & EMA (2006) \\
\hline Favipiravir & Lethal doses were $2000 \mathrm{mg} / \mathrm{kg}$ in mice, $2000 \mathrm{mg} / \mathrm{kg}$ in rats, and $1000 \mathrm{mg} / \mathrm{kg}$ in dogs & PubChem (2021) \\
\hline Ribavirin & NOEC for growth inhibition in algae was less than $100 \mathrm{mg} / \mathrm{L}$ & Roche (2020) \\
\hline Oseltamivir & $\begin{array}{l}\text { NOEC for both oseltamivir and oseltamivir carboxylate was } 1 \mathrm{mg} / \mathrm{L} \text { in algae, fish, and } \\
\text { daphnia }\end{array}$ & Straub (2009) \\
\hline Umifenovir & Oral $\mathrm{EC}_{50}$ was $340-400 \mathrm{mg} / \mathrm{kg}$ in mice and $>3000 \mathrm{mg} / \mathrm{kg}$ in rats & Drugbank (2021) \\
\hline Remdesivir & No ecotoxicological data, hence further research is needed & Cayman Chemical Co. (2020) \\
\hline
\end{tabular}

NOEC no observable-effect concentration, EC50 half-maximal effective concentration

a comprehensive discussion of the ecotoxicology of all the therapeutic drugs is beyond the scope of the present review. Here, a summary of the ecotoxicological effects of some of the COVID-19 therapeutic drugs is presented (Table 3).

To date, a number of aquatic organisms have been used to investigate the ecotoxicology of the therapeutics drugs, including freshwater and terrestrial organisms (Table 3). The aquatic ecotoxicology of ivermectin and niclosamide is relatively well-documented compared to other COVID19 therapeutic drugs (Leak et al. 2020; Mesa et al. 2017; Montforts et al. 2003; Hepditch et al. 2021). The $\mathrm{EC}_{50}$ of ivermectin in Daphnia magna was $25 \mathrm{ng} / \mathrm{L}$ while the predicted NOEC for an invertebrate was about $10 \mathrm{ng} / \mathrm{L}$ (Montforts et al. 2003). Using rainbow trout (Oncorhynchus mykiss) as a bioassay species, the EC50 of niclosamide was estimated to be $0.11 \mathrm{mg} / \mathrm{L}$ (Hepditch et al. 2021).

Both hydroxychloroquine and chloroquine are reported to pose adverse health risks to aquatic organisms. For example, the half-maximal effective concentration $\left(\mathrm{EC}_{50}\right)$ for chloroquine to induce an adverse response in crustacean Daphnia magna is $12 \mu \mathrm{M}$ (Zurita et al. 2005). For algae, ritonavir has as a low predicted no observable-effect concentration (NOEC) of $1.59 \mathrm{mg} / \mathrm{L}$ (EMA 2006) while ribavirin has a NOEC of less than $100 \mathrm{mg} / \mathrm{L}$ for growth inhibition in algae (Roche 2020). Thus, higher concentrations exceeding the predicted NOEC cause severe adverse effects in aquatic organisms such as algae. Both oseltamivir and oseltamivir carboxylate have NOEC of $1 \mathrm{mg} / \mathrm{L}$ in algae, fish, and $D$. magna (Straub et al. 2009). However, currently nto ecotoxicology data available for remdesivir which has been reported to have a potential for COVID-19 treatment.
The ecotoxicity of antiviral such as favipiravir has also been reported in terrestrial and domesticated animals. For example, favipiravir is teratogenic, and data based on singledose oral exposure showed low lethal toxicity to mice, rat and dogs at concentrations exceeding $1000 \mathrm{mg} / \mathrm{kg}$ in dogs, and $2000 \mathrm{mg} / \mathrm{kg}$ in both mice and rats (PubChem 2021). These data point to the need to develop and implement mitigation measures to minimize the potential ecological health risks. The overall effect of the outbreak of COVID-19 is to increase both the prevalence and concentrations of these drugs and their metabolites in the environment and aquatic systems. In turn, the increase in concentrations in environmental media including aquatic systems may exceed the ecotoxicological thresholds (e.g. NOEC, $\mathrm{EC}_{50}$ ) required to induce adverse effects in terrestrial and aquatic organisms.

\section{Environmental risk assessment}

The widespread use of pharmaceuticals to treat COVID-19 related ailments may contribute to the discharge of concentrations high enough to elicit adverse effects in aquatic biota. Several regulatory agencies such as the European Medicines Agency (EMA), US Food and Drug Administration (US FDA), China National Medical Products Administration, and Australia Therapeutic Goods Administration require that the environmental risk of pharmaceuticals be assessed quantitatively. In 2015, the European Union added two COVID-19 related pharmaceuticals (i.e. clarithromycin and azithromycin) to a watch list of emerging contaminants. Predicted or measured environmental concentrations (PEC or MEC), predicted or measured intrinsic toxicity (PNEC or NOEC), and the environmental fate and transport of the 
pharmaceuticals are used to establish the probability of the pharmaceutical to cause an adverse effect. The PEC is estimated from daily drug dose $\left(D_{\mathrm{d}}\right)$, fraction of pharmaceutical excreted by humans following administration $(f)$, number of people taking the pharmaceutical per population of 100,000 $\left(N_{\mathrm{t}}\right)$, wastewater generated per inhabitant $\left(W_{\mathrm{c}}\right)$, and wastewater removal efficiency $(R)$ (see Eqs. (1)-(3) in "A summary of early results" section).

The EMA recommends $N_{\mathrm{t}}$ and $W_{\mathrm{c}}$ values of 100 people and $200 \mathrm{~L}$, respectively. When the PEC in the aquatic environment exceeds $0.1 \mu \mathrm{g} / \mathrm{L}$ in the US or $0.01 \mu \mathrm{g} / \mathrm{L}$ in the EU, a complete environmental risk assessment is required prior to approval. However, the EMA and FDA regulations overlook the following aspects: (1) potential changes in dosage when pharmaceuticals are repurposed, (2) drastic increase in population taking medication due to a pandemic, and (3) changes in volume of wastewater produced due to illness. For example, between December 2020 and February 2021, Los Angeles County in the USA had an $N_{\mathrm{t}}>100$ cases per 100,000 population, reaching a peak of 150 cases per 100,000 population on 1 January, 2021. In addition, previous studies found that among people with Covid-19, 19.4\% experienced diarrhoea while 3.6-15.9\% experienced vomiting, suggesting COVID-19 may increase the Wc values. Therefore, EMA and US FDA guidelines are probably not adequate for estimating the exposure risk of pharmaceuticals during pandemics caused by bacteria and viruses. Nevertheless, a recent study found the PEC in rivers of oseltamivir, umifenivor, chloroquine, hydroxychloroquine, teicoplanin, and ribavarin where above $0.01 \mu \mathrm{g} / \mathrm{L}$.

The single compound toxicity model used to estimate the risk of pollutants is probably inadequate for estimating the risk of COVID-19 related pharmaceuticals. Environmental risk is determined using the ratio of PEC in aquatic environments and the highest concentration of the pharmaceutical that elicit no adverse effects in a specific aquatic organism (PNEC). Kuroda et al. (2021) predicted that the ecotoxicological risk was high (risk quotient $>1.0$ ) for lopinavir and umifenivor, medium $(1.0>$ risk quotient $>0.1)$ for hydroxychloroquine, remdesivir, and ritonavir, and low (risk quotient $<0.1$ ) for chloroquine, dexamethasone, and oseltamivir. There are four factors that limit the adequacy of single compound toxicity approach in environmental risk assessment. Firstly, contrasting PNEC values can be obtained since the biological endpoints used to determine PNEC values can be based on chronic or acute toxicity or derived from exposures in different species (normally fish, daphnia, and algae). Secondly, acute toxicity endpoints may not adequately demonstrate the potential of the pharmaceuticals to elicit chronic effects following chronic exposure at sub-acute concentrations. However, when chronic toxicity data are not available, acute toxicity data may be used when permissible by the specific mode of action. Thirdly, considering different pharmaceutical classes are used for treating COVID-19 and its associated symptoms, an array of COVID-19 related pharmaceuticals is discharged into the environment. Hence, aquatic biota are exposed to a mixture of COVID-19 related pharmaceuticals which can act synergistically, antagonistically, or additively. Finally, most of the COVID-19 related pharmaceuticals such as chloroquine, fluoxetine, tramadol, ritonavir, oseltamivir, and remdesivir are chiral compounds with at least one chiral centre. Enantiomers of chiral pharmaceuticals often have different toxicities; hence, pharmaceuticals should be treated as mixtures rather than single compounds (Sanganyado et al., 2017, 2020). Recent studies explored the use of molecular docking in determining the risk of pollutants using adverse outcome pathway approach. Interestingly, when the primary drug target in aquatic organisms is known, molecular docking can be used to predict the toxicity of a pharmaceutical enantioselectively. However, there is a need for additional studies to explore the utility of coupling molecular docking and adverse outcome pathways in assessing the risk of chiral pharmaceuticals in aquatic environments.

\section{Preventive and mitigation strategies}

Pharmaceutical companies and nongovernmental organizations agreed in 2015 that the environment had to be protected from pharmaceutical pollution (Miller et al. 2018). Although the agreement was weak because it had no specific and legally binding demands on pharmaceutical pollution mitigation or data sharing between manufacturers and scientists, it provoked the development of comprehensive regulatory frameworks for managing pharmaceuticals and their waste to reduce environmental impacts by many regional and national bodies (Miller et al. 2018). Over the years, there has been a shift from regulating past pollution events towards mitigating and diminishing future adverse environmental effects. This new regulatory paradigm requires that the pharmaceutical companies provide data on the potential ecological risk posed by their new pharmaceutical compounds prior to introduction to the market. Such data can be valuable for assessing the environmental impact of repurposed drugs whose consumption drastically increases due to pandemics.

\section{Wastewater treatment}

The environmental impacts of pharmaceuticals can be minimized by removing the pharmaceuticals from the environment (pollution clean-up) or controlling pharmaceutical discharge into the environment (ecopharmacovigilance). Pollution clean-up is concerned with decreasing the levels of pharmaceuticals in environmental matrices after a contamination event. Wastewater treatment plants are the most used pollution clean-up approaches (Ramiro et al. 2021; 
Abhradeep et al. 2021). The removal efficiency of COVID19 related pharmaceuticals is low following primary and secondary treatment, but can be high following tertiary treatment. For example, a study in Germany found that conventional wastewater treatment plants could not remove oseltamivir from the effluent, but removed $59 \%$ of its metabolite oseltamivir carboxylate. Other studies confirmed that oseltamivir was not biodegradable in conventional wastewater treatment plants or under direct photolysis. In South Africa, the removal efficiency of ritonavir, lopinavir, and darunavir at three conventional wastewater treatment plants were $60-95 \%$, none- $43 \%$, and none-66\%, respectively. A pilot membrane bioreactor plant at a hospital in Switzerland removed clarithromycin $(50 \pm 12 \%)$, oseltamivir carboxylate $(18 \pm 62 \%)$, and paracetamol (>99\%) but could not remove oseltamivir. Using adsorption approach, a recent study found nanofibres fabricated from Mondia whitei roots removed more than $90 \%$ of ritonavir and dexamethasone in wastewater effluent at $\mathrm{pH} 5$ and 7.

In surface water, COVID-19 related therapeutic drugs are susceptible to direct photodegradation through the absorption of a photon, and indirect photodegradation which is mediated by various reactive species such as photo-excited natural organic matter, hydroxyl radicals, and peroxyl radicals (Packer et al. 2003). Natural organic matter can enhance the photodegradation rates of drugs such as ibuprofen and amoxicillin which are relatively photostable. In contrast, natural organic matter can inhibit photo-oxidation of sulphonamide antibiotics by inhibiting the triplet-induced photodegradation transformation (Wenk et al. 2011) or compete for photons especially when the photodegradation products of the drug (e.g. sulfathiazole) have high quantum yield (Niu et al. 2018). In amine drugs such as propranolol and antipyrine, electron-transfer interaction between natural organic matter and the amine drugs was influenced by the presence of available $\mathrm{N}$-electrons and a hydrogen atom on the $\alpha$-carbon on the amine functional group (Chen et al. 2009). However, previous studies have shown that photoexcitation of therapeutic drugs such as psychotropic and nonsteroidal anti-inflammatory drugs elicit phototoxicity by generating singlet oxygen and superoxide (Trawiński and Skibiński 2017).

In recent years, several advanced oxidation/reduction processes have been developed as alternatives for the slower and less efficient natural photodegradation. Heterogenous photocatalysts (Fenton-like processes) such as metal oxides (e.g. $\mathrm{TiO}_{2}$ and $\mathrm{ZnO}$ ) are sometimes used to generate reactive species that facilitate the photodegradation of therapeutic drugs in aquatic systems (Orimolade et al. 2021). While both $\mathrm{TiO}_{2}$ and $\mathrm{ZnO}$ are highly photoreactive, relatively inexpensive, abundant, and effective photocatalysts, they often require UV irradiation for excitation since their bandgap energies are large (Orimolade et al. 2021). However, heterogenous catalysts are susceptible to deactivation over time (since they operate at a limited $\mathrm{pH}$ range) and have low contact time. A recent study found that diclofenac was removed $(65 \%)$ and mineralized ( $48 \%$ ) by a catalytic membrane reactor that comprised of porous alumina support material in tubular form and iron oxide nanoparticles embedded in the pores (Plakas et al. 2019). The porous and tubular support materials helped improve the contact time of the photocatalyst. Additionally, carbon materials are often used in advanced oxidation/reduction processes as doping materials (e.g. carbon nanotubes, carbon quantum dots, or biochar) or as supports (e.g. as electrodes) because they improve photoactivity by enhancing electron-transfer interactions (Mestre and Carvalho 2019). Previous studies have shown that therapeutic drugs such as acetaminophen, ciprofloxacin, propranolol, and trimethoprim were rapidly $(>80 \%, 3 \mathrm{~h})$ transformed in latrine wastewater via electrochemical oxidation using mixed-metal oxide anodes and stainless-steel cathodes (Jasper et al. 2016). The results demonstrated that electrochemical oxidation supported by solar power could be used for treating wastewater on-site in regions that have poor wastewater and energy infrastructure. Additionally, reactive species can be produced by chemicals such as ozone (Leresche et al. 2019), periodate, and hydroxylamine (Sun et al. 2020). However, using periodate and hydroxylamine poses serious ecological challenges since it requires potentially toxic reagents, elicits water acidification, rarely mineralizes the pollutants, and often produces potentially toxic transformation products (Sun et al. 2020).

Hybrid wastewater treatment comprising of conventional configurations (primary and secondary treatment) and membrane bioreactors along with advanced post-treatment methods such as advanced oxidation processes (ozonation, Fenton oxidation, photocatalysis, and electrochemical oxidation) and adsorption (e.g. activated carbon and nanoparticles) have been proposed to improve removal of pharmaceuticals in wastewater (Lei et al. 2021a, b; Junye et al. 2021).

\section{Ecopharmacovigilance}

Ecopharmacovigilance approaches pharmaceutical pollution mitigation from the drug administration perspective to detect, evaluate, understand, and prevent ecological risk posed by pharmaceuticals. For example, the antimicrobial stewardship initiatives seek to reduce antimicrobial resistance in the environment by educating and encouraging the public, health practitioners, and policy-makers to reduce overuse, abuse, and misuse of antimicrobial drugs. By emphasizing prevention of pharmaceutical pollution and assessing environmental risk prior to market approval, regulatory agencies such as EMA have adopted the ecopharmacovigilance approach. For example, the EU's Pharmacovigilance Framework recommends that member states should 
put in place measures to monitor and evaluate the ecological risk of pharmaceuticals. However, for the ecopharmacovigilance approach to be effective, it requires real-time and accessible data on the consumption, production, and environmental discharge (i.e. concentration and sources) of pharmaceuticals. The current scarcity of data on consumption and pharmaceutical pollution due to the COVID-19 pandemic provides evidence for the need for a multi-sectoral pharmaceutical emission management system that covers pharmaceutical use in hospitals as well as over-the-counter drugs. Furthermore, COVID-19 related pharmaceuticals are a diverse group of compounds with different physicochemical, pharmacological, and ecotoxicological characteristics. Extensive monitoring and evaluating them during or after the COVID-19 pandemic is impractical. Hence, previous studies on pharmaceuticals in general recommended targeted ecopharmacovigilance where pharmaceuticals are first prioritized based on volume of use, intrinsic ecotoxicity, and exposure risk. For that reason, antibiotics and antiviral drugs which are known to promote resistance in bacteria and viruses can be targeted for ecopharmacovigilance when focusing on COVID-19 related pharmaceuticals.

\section{Perspectives}

The present review draws from existing data and material safety data sheets to infer the behaviour, fate and health risks of old and repurposed COVID-19 therapeutic drugs. The potential hotspot sources of such drugs were also discussed, but understandably, given that COVID-19 is a recent pandemic, dedicated studies investigating these aspects following the outbreak of COVID-19 are still limited. Here, future research needs are highlighted using the source-pathwayreceptor-impact continuum as an organizing framework to track therapeutic drugs.

\section{Sources and occurrence of therapeutic drugs}

Studies investigating the nature, occurrence, and concentrations of therapeutic drugs are required targeting wastewaters and receiving aquatic systems associated with the potential hotspots identified in the current study. These include pharmaceutical industries, quarantine centres, human heathcare facilities, and households in communities with high COVID19 cases. Besides the parent drugs, such studies should also determine the nature and concentrations of the degradation by-products or metabolites. To understand the impacts of COVID-19 on aquatic systems, such data should be compared with the corresponding values for the pre-COVID-19 period. Besides the drugs discussed in the current study, records or information from quarantine centres, health care facilities, and households on common prescribed and of-the-counter drugs used to treat COVID-19 and associated systems can be used to determine the drugs to target in aqueous systems. Such studies should also determine the discharges from the various sources in order to estimate total loads of drugs released from the various sources. Besides identification of point sources, tools such as wastewaterbased epidemiology or surveillance of drugs and their metabolites can be used to gain a better understanding of the prevalence of use of various COVID-19 drugs at suburban, district, and catchment scales.

\section{Behaviour and fate of therapeutic drugs}

The short-and long-term behaviour and fate of therapeutic drugs and their toxic metabolites in various aquatic systems require further investigation. These aquatic systems include on-site sanitation systems such as pit latrines and septic tanks commonly used in low-income settings, and receiving surface water and groundwater systems including those used as drinking water sources. Moreover, the behaviour and fate of drugs in wastewater and water treatment systems based on conventional and advanced treatment processes require further investigation. In low-income countries particular attention should be paid to drinking water sources close to wastewater and on-site sanitation systems. Equally important is the need to understand whether or not metabolites of such drugs are more toxic to aquatic organisms and humans than the parent compounds. Data on behaviour and fate are critical in determining the final concentrations of drugs and their metabolites to which aquatic organisms and human are exposed.

\section{Environmental exposure pathways}

Various exposure pathways may contribute to the intake of drugs and their metabolites by aquatic organisms and humans. In the case of humans, this includes via dermal contact, inhalation, and ingestion in contaminated water and food. Thus, there is need to investigate the following: (i) the nature and concentrations of drugs and their metabolites taken via the various routes, and (ii) the probability and relative contribution of the various pathways to the total burden of therapeutic drugs in aquatic organisms and humans, and (iii) identification of the receptors or aquatic organisms and humans at high risk of exposure to drugs in aquatic systems. Such studies may require determining the uptake, bioaccumulation, biotransformation, and fate at trophic levels along the aquatic and human food chains. Such data are also critical in quantitative assessment of ecotoxicological and human health risks. 


\section{Ecotoxicological and human health risks}

Inferential evidence points to the ecotoxicological health risks of drugs to aquatic organisms. However, COVID-19 may increase both the types and concentrations of drugs and their metabolites in aquatic environments. Hence, the impacts could be more significant thant currently reported in the literature. Studies are required to quantitatively estimate the ecotoxicological and human health risks of the drugs at environmentally relevant concentrations under typical real-life conditions. While earlier studies were limited to single drugs, such future studies should also address the following: (1) determine the nature of interactions among various drugs and their metabolites, including synergistic, antagonistic, and neutral effects, and (2) interactions between COVID-19 drugs and their metabolites, and other aquatic and human health stressors. An understanding of the ecotoxicological health risks should consider the various levels of biological organization. This includes genotoxicity, teratogenicity, mutagenicity, reproductive toxicity, organ toxicity, behavioural effects such as info-disruption, and disruption of ecosystem function, trophic interactions, and ecosystem goods and services. In the case of human health, such studies can be complemented with case-control toxicological and epidemiological studies to determine whether or not the prevalence and incidences of certain human health conditions/outcomes are significantly associated with exposure to drugs in aquatic systems via the various exposure routes.

\section{Conclusion}

The present perspective investigated the nature, sources, behaviour, fate, and potential environmental health risks of COVID-19 related therapeutic drugs in aquatic systems. The COVID-19 related drugs commonly used belong to a wide range of categories including: (1) veterinary medicines, (2) nonsteroidal anti-inflammatory drugs, (3) protein and peptide therapeutics, (4) disease-modifying anti-rheumatic drugs and anti-malarials, (5) antiretrovirals, (6) analgesics, and (7) supporting agents. COVID-19 therapeutic drugs include, among others, remdesivir, hydroxychloroquine, lopinavir, interferon regimens, paracetamol, ibuprofen, umifenovir (Arbidol), favipiravir (Avigan), oseltamivir (Tamiflu), and Ivermectin. Supporting agents include interleukin 6 (IL-6) antagonists, nitric oxide, ascorbic acid, corticosteroids, and azithromycin. Prescribed and of-the counter therapeutic drugs and their metabolites are excreted via faeces and urine of COVID-19 infected people into wastewater and on-site sanitation systems.

Potential sources of COVID-19 related drugs and their metabolites include in wastewater/effluents from pharmaceuticals industries producing such drugs, quarantine centres, healthcare facilities, and households. Once in on-site sanitation and wastewater treatment systems, drugs and their metabolites are released into surface water and groundwater systems via multiple pathways, including: (1) direct discharges of raw, partially treated, and treated wastewaters, (2) run-off and seepages, (3) infiltration and groundwater recharge, and (4) surface water-groundwater interactions. The behaviour and fate of the drugs in aquatic environments were discussed, including: (1) physicochemical processes such photodegradation, sorption/phase partitioning, and removal via wastewater treatment processes, and (2) biouptake, bioaccumulation, and biotransformation in aquatic organisms. However, available evidence, including information provided in material safety data sheets is silent on the degradation mechanisms and the behaviour and fate of metabolites of such therapeutic drugs.

The potential ecotoxicological risks including acute and chronic toxicity were summarized. However, data on impacts on ecosystem functions and trophic interactions in aquatic organisms are still limited. Moreover, currently, no data exist on human health risks associated with human exposure via drinking water and aquatic foods contaminated with COVID-19 therapeutic drugs. Future research directions, including knowledge gaps on sources, estimation of contaminant loads, behaviour and fate, removal in wastewater treatment systems, and health risks are presented.

Acknowledgements The research received no funding from private and public sources. We thank the two anonymous reviewers for comments that greatly improved the scope and presentation of the manuscript.

Author's contribution WG: Conceived the topic of the paper, conceptualization, methodology, investigation, formal analysis, visualization, writing - original draft, review, editing, finalization and revision. RS, N-AOO, AEDM, ES, JM: Methodology, investigation, formal analysis, visualization, writing — original draft, review and editing.

\section{Declaration}

Conflict of interest The authors declare that they have no known competing financial interests or personal relationships that could have appeared to influence the work reported in this paper.

\section{References}

Abhinandan K, Singh P, Raizada P, Hussain CM (2021) Impact of COVID-19 on greenhouse gases emissions: a critical review. Sci Total Environ 806:150349. https://doi.org/10.1016/j.scito tenv.2021.150349

Abhishek N, Siddiqui NA, Chandrakant S, Ashish A, Gwenzi W, Ighalo JO, Nagliate PC, Meili L, Singh P, Chaukura N, Rangabhashiyam S (2021) COVID-19 pandemic in Uttarakhand, India: environmental recovery or degradation? J Environ Chem Eng 9:106595. https://doi.org/10.1016/j.jece.2021.106595 
Abhradeep M, Ashok KG, Partha SG, Mahesh V (2021) A review on hospital wastewater treatment: a special emphasis on occurrence and removal of pharmaceutically active compounds, resistant microorganisms, and SARS-CoV-2. J Environ Chem Eng 9:104812. https://doi.org/10.1016/j.jece.2020.104812

Acree WE Jr, Grubbs LM, Abraham MH (2012) Prediction of toxicity, sensory responses and biological responses with the Abraham model. In: Acree WE Jr (ed) Toxicity and drug testing. InTech, Rijeka, pp 261-296

Ahmad I, Ahmed S, Anwar Z, Sheraz MA, Sikorski M (2016) Photostability and photostabilization of drugs and drug products. Int $\mathbf{J}$ Photoenergy 2016:1-19. https://doi.org/10.1155/2016/8135608

Ahmed W, Angel N, Edson J, Bibby K, Bivins A, Brien JWO, Choi PM, Kitajima M, Simpson SL, Li J (2020) First confirmed detection of SARS-CoV-2 in untreated wastewater in Australia: a proof of concept for the wastewater surveillance of COVID-19 in the community. Sci Total Environ 728:138764. https://doi.org/ 10.1016/j.scitotenv.2020.138764

Arsand DR, Kümmerer K, Martins AF (2013) Removal of dexamethasone from aqueous solution and hospital wastewater by electrocoagulation. Sci Total Environ 443:351-357. https://doi.org/10. 1016/j.scitotenv.2012.10.100

aus der Beek T, Weber F-A, Bergmann A, Gruttner G, Carius A (2016) Pharmaceuticals in the environment: global occurrence and potential cooperative action under the strategic approach to international chemicals management. Ger Fed Environ Agency 35:94. https://doi.org/10.1002/etc.3339

Bartels P, von Tümpling W (2008) The environmental fate of the antiviral drug oseltamivir carboxylate in different waters. Sci Total Environ 405:215-225. https://doi.org/10.1016/j.scitotenv.2008. 06.032

Bensalah N, Midassi S, Ahmad MI, Bedoui A (2020) Degradation of hydroxychloroquine by electrochemical advanced oxidation processes. Chem Eng J 402:126279. https://doi.org/10.1016/j. cej.2020.126279

Bhandari A, Close LI, Kim W, Hunter RP, Koch DE, Surampalli RY (2008) Occurrence of ciprofloxacin, sulfamethoxazole, and azithromycin in municipal wastewater treatment plants. Pract Period Hazard Toxic Radioact Waste Manag 12:275-281. https:// doi.org/10.1061/(ASCE)1090-025X(2008)12:4(275)

Biswas P, Mehedi Hasan M, Dey D, Dos Santos C, Costa A, Ahmed Polash S, Bibi S, Ferdous N, Abu Kaium M, Hasanur Rahman MD, Kamal Jeet F, Papadakos S, Islam K, Sahab Uddin M (2021) Candidate antiviral drugs for COVID-19 and their environmental implications: a comprehensive analysis. Environ Sci Pollut Res Int 12:1-24. https://doi.org/10.1007/s11356-021-16096-3

Bocci G, Bradfute SB, Ye C, Garcia MJ, Parvathareddy J, Reichard W, Surendranathan S, Bansal S, Bologa CG, Perkins DJ, Jonsson CB, Sklar LA, Oprea TI (2020) Virtual and in vitro antiviral screening revive therapeutic drugs for COVID-19. ACS Pharmacol Transl Sci 3:1278-1292. https://doi.org/10.1021/acsptsci. 0c00131

Boreen AL, Arnold WA, McNeill K (2003) Photodegradation of pharmaceuticals in the aquatic environment: a review. Aquat Sci 65:320-341. https://doi.org/10.1007/s00027-003-0672-7

Briones RM, Sarmah AK, Padhye LP (2016) A global perspective on the use, occurrence, fate and effects of anti-diabetic drug metformin in natural and engineered ecosystems. Environ Pollut 219:1007-1020. https://doi.org/10.1016/j.envpol.2016.07.040

Burki T (2021) Global COVID-19 vaccine inequity. NEWSDESK 21:922-923

Cayman Chemical Co. (2020) Cayman safety data sheet. Cayman Chemical Co., Ann Arbor
Chen Y, Hu C, Hu X, Qu J (2009) Indirect photodegradation of amine drugs in aqueous solution under simulated sunlight. Environ Sci Technol 43:2760-2765. https://doi.org/10.1021/es803325j

Chițescu CL, Nicolau AI (2014) Preliminary survey of pharmaceutical residues in some important Romanian rivers. Toxicol Environ Chem 96(9):1333-1345

Čizmić M, Ljubas D, Rožman M, Ašperger D, Ćurković L, Babíc S (2019) Photocatalytic degradation of azithromycin by nanostructured $\mathrm{TiO}_{2}$ film: kinetics, degradation products, and toxicity. Materials (basel) 12:873. https://doi.org/10.3390/ma12060873

Dabić D, Babić S, Škorić I (2019) The role of photodegradation in the environmental fate of hydroxychloroquine. Chemosphere 230:268-277. https://doi.org/10.1016/j.chemosphere.2019.05. 032

Drożdżal S, Rosik J, Lechowicz K, Machaj F, Kotfis K, Ghavami S, Łos MJ (2020) FDA approved drugs with pharmacotherapeutic potential for SARS-CoV-2 (COVID-19) therapy. Drug Resist Updates 53:100719. https://doi.org/10.1016/j.drup.2020.100719

DrugBank (2021) Umifenovir Product information. https://go.drugb ank.com/drugs/DB13609. Accessed 10 Feb 2020

El-Din Abuo-Rahma GA, Mohamed MFA, Ibrahim TS, Shoman ME, Samir E, Abd El-Baky RM (2020) Potential repurposed SARSCoV-2 (COVID-19) infection drugs. RSC Adv 10:26895-26916. https://doi.org/10.1039/d0ra05821a

Elkayam R, Aharoni A, Vaizel-Ohayon D, Sued O, Katz Y, Negev I et al (2018) Viral and microbial pathogens, indicator microorganisms, microbial source tracking indicators, and antibiotic resistance genes in a confined managed effluent recharge system. J Environ Eng 144:05017011. https://doi.org/10.1061/(ASCE) EE.1943-7870.0001334

Escher BI, Berger C, Bramaz N, Kwon JH, Richter M, Tsinman O, Avdeef A (2008) Membrane-water partitioning, membrane permeability, and baseline toxicity of the parasiticides ivermectin, albendazole, and morantel. Environ Toxicol Chem 27:909-918. https://doi.org/10.1897/07-427.1

Espejo W, Celis JE, Chiang G, Bahamonde P (2020) Environment and COVID-19: pollutants, impacts, dissemination, management and recommendations for facing future epidemic threats. Sci Total Environ 747:141314. https://doi.org/10.1016/j.scitotenv.2020. 141314

Essid N, Allouche M, Lazzem M, Harrath AH, Mansour L, Alwasel S, Mahmoudi E, Beyrem H, Boufahja F (2020) Ecotoxic response of nematodes to ivermectin, a potential anti-COVID-19 drug treatment. Mar Pollut Bull 157:111375. https://doi.org/10.1016/j. marpolbul.2020.111375

European Medicines Agency (EMA) (2006) Guideline on the environmental risk assessment of medicinal products for human use. European Medicines Agency, Committee for Medicinal Products for Human Use (CHMP), EMA/CHMP/SWP/447/00 corr 2. London, UK. Available at: https://www.ema.europa.eu/en/ environmentalrisk-assessment-medicinal-products-human-use. Accessed 5 July 2021

FASS (2019) FASS safety data sheet, 2019. Environmental risk assessment summary Plaquenil. FASS, London

Fick J, Lindberg RH, Tysklind M, Haemig PD, Waldenström J, Wallensten A, Olsen B (2007) Antiviral oseltamivir is not removed or degraded in normal sewage water treatment: implications for development of resistance by influenza A virus. PLoS ONE 2:e986. https://doi.org/10.1371/journal.pone.0000986

Fick J, Lindberg RH, Tysklind M, Larsson DGJ (2010) Predicted critical environmental concentrations for 500 pharmaceuticals. Regul Toxicol Pharmacol 58:516-523. https://doi.org/10.1016/j.yrtph. 2010.08.025

Fittler A, Adeniye L, Katz Z, Bella R (2021) Effect of infodemic regarding the illegal sale of medications on the internet: evaluation of 
demand and online availability of ivermectin during the COVID19 pandemic. Int J Environ Res Public Health 18:7475. https:// doi.org/10.3390/ijerph18147475

Galani A, Alygizakis N, Aalizadeh R, Kastritis E, Dimopoulos MA, Thomaidis NS (2021) Patterns of pharmaceuticals use during the first wave of COVID-19 pandemic in Athens, Greece as revealed by wastewater-based epidemiology. Sci Total Environ 798:149014. https://doi.org/10.1016/j.scitotenv.2021.149014

Ghosh GC, Nakada N, Yamashita N, Tanaka H (2010) Occurrence and fate of oseltamivir carboxylate (Tamiflu) and amantadine in sewage treatment plants. Chemosphere 81:13-17. https://doi.org/ 10.1016/j.chemosphere.2010.07.023

Goodarzi N, Barazesh Morgani A, Abrahamsson B, Cristofoletti R, Groot DW, Langguth P, Mehta MU, Polli JE, Shah VP, Dressman JB (2016) Biowaiver monographs for immediate release solid oral dosage forms: ribavirin. J Pharm Sci 105:1362-1369. https:// doi.org/10.1016/j.xphs.2016.01.017

Guibal R, Lissalde S, Guibaud G (2020) Experimental estimation of 44 pharmaceutical polar organic chemical integrative sampler sampling rates in an artificial river under various flow conditions. Environ Toxicol Chem 39:1186-1195. https://doi.org/10. 1002/etc. 4717

Gwenzi W, Chaukura N (2018) Organic contaminants in African aquatic systems: current knowledge, health risks, and future research directions. Sci Total Environ 619:1493-1514

Gwenzi W, Sanganyado E (2019a) Recurrent cholera outbreaks in subSaharan Africa: moving beyond epidemiology to understand the environmental reservoirs and drivers. Challenges 10:1. https:// doi.org/10.3390/challe10010001

Hanafin PO, Jermain B, Hickey AJ, Kabanov AV, Kashuba ADM, Sheahan TP, Rao GG (2020) A mechanism-based pharmacokinetic model of remdesivir leveraging interspecies scaling to simulate COVID-19 treatment in humans. CPT Pharmacometr Syst Pharmacol 10:89-99. https://doi.org/10.1002/psp4.12584

Hanamoto S, Ogawa F (2019) Predicting the sorption of azithromycin and levofloxacin to sediments from mineral and organic components. Environ Pollut 255:113180. https://doi.org/10.1016/j. envpol.2019.113180

Hepditch S, Birceanu O, Wilkie MP (2021) A toxic unit and additive index approach to understanding the interactions of two piscicides, TFM and niclosamide, in rainbow trout. Environ Toxicol Chem. https://doi.org/10.1002/etc.4994

Hussain A, Kaler J, Dubey AK (2020) Emerging pharmaceutical treatments of novel COVID-19: a review. Cureus 12:e8260. https:// doi.org/10.7759/cureus.8260

Jain S, Kumar P, Vyas RK, Pandit P, Dalai AK (2013) Occurrence and removal of antiviral drugs in environment: a review. Water Air Soil Pollut 224:1-19. https://doi.org/10.1007/s11270-012-1410-3

Jan F, Carsten P, Thomas AT (2016) Identification of transformation products of antiviral drugs formed during biological wastewater treatment and their occurrence in the urban water cycle. Water Res 98:75-83. https://doi.org/10.1016/j.watres.2016.03.045

Jasper JT, Shafaat OS, Hoffmann MR (2016) Electrochemical transformation of trace organic contaminants in latrine wastewater. Environ Sci Technol 50:10198-10208. https://doi.org/10.1021/ acs.est.6b02912

Jean SS, Hsueh PR (2020) Old and re-purposed drugs for the treatment of COVID-19. Expert Rev Anti-infect Therapy 18(9):843-847

Junye M, Daisuke M, Kevin OS, Lu B, Dionysios DD, Richard S, Ruiyang X, Zongsu W (2021) Determination and environmental implications of aqueous-phase rate constants in radical reactions. Water Res 190:116746. https://doi.org/10.1016/j.watres. 2020.116746

Keller VDJ, Williams RJ, Lofthouse C, Johnson AC (2014) Worldwide estimation of river concentrations of any chemical originating from sewage-treatment plants using dilution factors. Environ Toxicol Chem 33:447-452

Khan AH, Tirth V, Fawzy M, Mahmoud AED, Khan NA, Ahmed S, Ali SS, Akram M, Hameed L, Islam S, Das G (2021) COVID19 transmission, vulnerability, persistence and nanotherapy: a review. Environ Chem Lett $1-15$

Kumar M, Patel AK, Shah AV, Raval J, Rajpara N, Joshi M et al (2020a) First proof of the capability of wastewater surveillance for COVID-19 in India through detection of genetic material of SARS-CoV-2. Sci Total Environ 746:141326. https://doi.org/10. 1016/j.scitotenv.2020.141326

Kumar M, Kuroda K, Dhangar K, Mazumder P, Sonne C, Rinklebe J, Kitajima M (2020b) Potential emergence of antiviral-resistant pandemic viruses via environmental drug exposure of animal reservoirs. Environ Sci Technol 54:8503-8505. https://doi.org/ 10.1021/acs.est.0c03105

Kumar R, Sharma A, Srivastava JK, Siddiqui MH, Uddin MS, Aleya L (2021) Hydroxychloroquine in COVID-19: therapeutic promises, current status, and environmental implications. Environ Sci Poll Res $1-14$

Kumari M, Kumar A (2021) Can pharmaceutical drugs used to treat Covid-19 infection leads to human health risk? A hypothetical study to identify potential risk. Sci Total Environ 15:146303. https://doi.org/10.1016/j.scitotenv.2021.146303

Kuroda K, Li C, Dhangar K, Kumar M (2021) Predicted occurrence, ecotoxicological risk and environmentally acquired resistance of antiviral drugs associated with COVID-19 in environmental waters. Sci Total Environ 776:145740. https://doi.org/10. 1016/j.scitotenv.2021.145740

Leak T, Aufderheide J, Bergfield A, Hubert TD (2020) Acute toxicity of the lampricides TFM and niclosamide: effects on a vascular plant and a chironomid species. J Great Lakes Res 46(1):180187. https://doi.org/10.1016/j.jglr.2019.11.007

Lei H, Lu B, Dionysios DD, Zongsu W, Richard S, Chu C, Zhang L, Ruiyang X (2021a) Applications of computational chemistry, artificial intelligence, and machine learning in aquatic chemistry research. Chem Eng J 426:131810. https://doi.org/ 10.1016/j.cej.2021.131810

Lei H, Lingjun B, Richard S, Dionysios DD, Ruiyang X (2021b) Reactivity and reaction mechanisms of sulfate radicals with lindane: an experimental and theoretical study. Environ Res 201:111523. https://doi.org/10.1016/j.envres.2021.111523

Leresche F, McKay G, Kurtz T, von Gunten U, Canonica S, RosarioOrtiz FL (2019) Effects of ozone on the photochemical and photophysical properties of dissolved organic matter. Environ Sci Technol 53:5622-5632. https://doi.org/10.1021/acs.est. 8 b06410

Li Z, Sobek A, Radke M (2015) Flume experiments to investigate the environmental fate of pharmaceuticals and their transformation products in streams. Environ Sci Technol 49:6009-6017. https:// doi.org/10.1021/acs.est.5b00273

Li R, Cai M, Liu H, Liu G, Lv W (2018) Thermo-activated peroxydisulfate oxidation of indomethacin: kinetics study and influences of co-existing substances. Chemosphere 212:1067-1075. https://doi.org/10.1016/j.chemosphere.2018.08.126

Lindroos M, Hörnström D, Larsson G, Gustavsson M, van Maris AJA (2019) Continuous removal of the model pharmaceutical chloroquine from water using melanin-covered Escherichia coli in a membrane bioreactor. J Hazard Mater 365:74-80. https://doi.org/ 10.1016/j.jhazmat.2018.10.081

Löffler D, Römbke J, Meller M, Ternes TA (2005) Environmental fate of pharmaceuticals in water/sediment systems. Environ Sci Technol 39:5209-5218. https://doi.org/10.1021/es0484146

Love JS, Blumenberg A, Horowitz Z (2020) The parallel pandemic: medical misinformation and COVID-19: primum non nocere. 
J Gen Intern Med 35:2435-2436. https://doi.org/10.1007/ s11606-020-05897-w

Mahmoud AED (2020a) Graphene-based nanomaterials for the removal of organic pollutants: insights into linear versus nonlinear mathematical models. J Environ Manag 270:110911. https:// doi.org/10.1016/j.jenvman.2020.110911

Mahmoud AED (2020b) Nanomaterials: green synthesis for water applications. In: Kharissova OV, Martínez LMT, Kharisov BI (eds) Handbook of nanomaterials and nanocomposites for energy and environmental applications. Springer International Publishing, Cham, pp 1-21

Mahmoud AED et al (2020) Mechanochemical versus chemical routes for graphitic precursors and their performance in micropollutants removal in water. Powder Technol 366:629-640. https://doi.org/ 10.1016/j.powtec.2020.02.073

Matera MG, Rogliani P, Calzetta L, Cazzola M (2020) Pharmacological management of COVID-19 patients with ARDS (CARDS): a narrative review. Respir Med 171:106114. https://doi.org/10. 1016/j.rmed.2020.106114

McFarland JW, Berger CM, Froshauer SA, Hayashi SF, Hecker SJ, Jaynes BH, Jefson MR, Kamicker BJ, Lipinski CA, Lundy KM, Reese CP, Vu CB (1997) Quantitative structure-activity relationships among macrolide antibacterial agents: in vitro and in vivo potency against Pasteurella multocida. J Med Chem 40:13401346. https://doi.org/10.1021/jm960436i

McKee DL, Sternberg A, Stange U, Laufer S, Naujokat C (2020) Candidate drugs against SARS-CoV-2 and COVID-19. Pharmacol Res 157:104859. https://doi.org/10.1016/j.phrs.2020.104859

Mesa LM, Lindt I, Negro L, Gutierrez MF, Mayora G, Montalto L, Ballent M, Lifschitz A (2017) Aquatic toxicity of ivermectin in cattle dung assessed using microcosms. Ecotoxicol Environ Saf 144:422-429. https://doi.org/10.1016/j.ecoenv.2017.06.016

Mestankova H, Schirmer K, Escher BI, von Gunten U, Canonica S (2012) Removal of the antiviral agent oseltamivir and its biological activity by oxidative processes. Environ Pollut 161:30-35. https://doi.org/10.1016/j.envpol.2011.09.018

Mestre AS, Ana PC (2019) Photocatalytic degradation of pharmaceuticals carbamazepine, diclofenac, and sulfamethoxazole by semiconductor and carbon materials: a review. Molecules 24(20):3702. https://doi.org/10.3390/molecules24203702

Miller TH, Bury NR, Owen SF, MacRae JI, Barron LP (2018) A review of the pharmaceutical exposome in aquatic fauna. Environ Pollut 239:129-146. https://doi.org/10.1016/j.envpol.2018.04.012

Mohseni SN, Amooey AA, Tashakkorian H, Amouei AI (2016) Removal of dexamethasone from aqueous solutions using modified clinoptilolite zeolite (equilibrium and kinetic). Int $\mathbf{J}$ Environ Sci Technol 13:2261-2268. https://doi.org/10.1007/ s13762-016-1045-9

Montforts MHMM, Blackwell P, Boxall A, Halling-Sørensen B, Hermansen S, Ingerslev F, Jacobsen AM, Kay P, ter Laak T, Moltmann J, Schmitt H, Søeborg T, Tarazona J, Tolls J, Verschoor A (2003) ERAVMIS: environmental risk assessment of veterinary medicines in slurry. http://www.silsoe.cranfield.ac.uk/ecochemist ry/eravmis/eravguid1.pdf. Accessed 12 Feb 2021

Morgan CJ, Renwick AG, Friedmann PS (2003) The role of stratum corneum and dermal microvascular perfusion in penetration and tissue levels of water-soluble drugs investigated by microdialysis. Br J Dermatol 148:434-443. https://doi.org/10.1046/j.13652133.2003.05163.x

Mousazadeh M, Naghdali Z, Rahimian N, Hashemi M, Paital B, AlQodah Z, Mukhtar A, Karri RR, Mahmoud AED, Sillanpää M, Dehghani MH (2021) Management of environmental health to prevent an outbreak of COVID-19: a review. Environ Health Manag Novel Coronavirus Disease (COVID-19), pp 235-267

Muhammad U, Muhammad F, Khalil H (2020) Environmental side effects of the injudicious use of antimicrobials in the era of
COVID-19. Sci Total Environ 745:41053. https://doi.org/10. 1016/j.scitotenv.2020.141053

Ncube S, Madikizela LM, Chimuka L, Nindi MM (2018) Environmental fate and ecotoxicological effects of antiretrovirals: a current global status and future perspectives. Water Res 145:231-247. https://doi.org/10.1016/j.watres.2018.08.017

Nittari G, Pallotta G, Amenta F, Tayebati SK (2020) Current pharmacological treatments for SARS-COV-2: a narrative review. Eur J Pharmacol 882:173328. https://doi.org/10.1016/j.ejphar. 2020.173328

Niu XZ, Moore EG, Croue JP (2018) Excited triplet state interactions of fluoroquinolone norfloxacin with natural organic matter: a laser spectroscopy study. Environ Sci Technol 52:10426-10432. https://doi.org/10.1021/acs.est.8b02835

Nord K, Karlsen J, Tønnesen HH (1991) Photochemical stability of biologically active compounds. IV. Photochemical degradation of chloroquine. Int J Pharm 72:11-18. https://doi.org/10.1016/ 0378-5173(91)90375-X

Offiong NAO, Inam EJ, Edet JB (2019) Preliminary review of sources, fate, analytical challenges and regulatory status of emerging organic contaminants in aquatic environments in selected African Countries. Chem Africa. https://doi.org/10.1007/ s42250-019-00079-6

O'Flynn D, Harold D, Holland L, Parle-McDermott A, Lawler J, McCloughlin T et al (2021) A review of pharmaceutical occurrence and pathways in the aquatic environment in the context of a changing climate and the COVID-19 pandemic. Anal Methods. https://doi.org/10.1039/D0AY02098B

Oikonomou E, Aznaouridis K, Barbetseas J, Charalambous G, Gastouniotis I, Fotopoulos V, Gkini K-P, Katsivas A, Koudounis G, Koudounis P, Koutouzis M, Lamprinos D, Lazaris E, Lazaris E, Lazaros G, Marinos G, Platogiannis N, Platogiannis D, Siasos G, Terentes-Printzios D, Theodoropoulou A, Theofilis P, Toutouzas K, Tsalamandris S, Tsiafoutis I, Vavouranakis M, Vogiatzi G, Zografos T, Baka E, Tousoulis D, Vlachopoulos C (2020) Hospital attendance and admission trends for cardiac diseases during the COVID-19 outbreak and lockdown in Greece. Public Health 187:115-119. https://doi.org/10.1016/j.puhe.2020.08.007

Orimolade BO, Idris AO, Feleni U, Mamba B (2021) Recent advances in degradation of pharmaceuticals using $\mathrm{Bi}_{2} \mathrm{WO}_{6}$ mediated photocatalysis - a comprehensive review. Environ Pollut 289:117891. https://doi.org/10.1016/j.envpol.2021.117891

Packer JL, Werner JJ, Latch DE, McNeill K, Arnold WA (2003) Photochemical fate of pharmaceuticals in the environment: naproxen, diclofenac, clofibric acid, and ibuprofen. Aquat Sci 65:342-351. https://doi.org/10.1007/s00027-003-0671-8

Patel M, Kumar R, Kishor K, Mlsna T, Pittman CU, Mohan D (2019) Pharmaceuticals of emerging concern in aquatic systems: chemistry, occurrence, effects, and removal methods. Chem Rev 119:3510-3673. https://doi.org/10.1021/acs.chemrev.8b00299

Plakas KV, Mantza A, Sklari SD, Zaspalis VT, Karabelas AJ (2019) Heterogeneous Fenton-like oxidation of pharmaceutical diclofenac by a catalytic iron-oxide ceramic microfiltration membrane. Chem Eng J 373:700-708. https://doi.org/10.1016/j.cej. 2019.05.092

Prasse C, Löffler D, Ternes TA (2009) Environmental fate of the anthelmintic ivermectin in an aerobic sediment/water system. Chemosphere 77:1321-1325. https://doi.org/10.1016/j.chemosphere. 2009.09.045

Prasse C, Schlüsener MP, Schulz R, Ternes TA (2010) Antiviral drugs in wastewater and surface waters: a new pharmaceutical class of environmental relevance? Environ Sci Technol 44:1728-1735. https://doi.org/10.1021/es903216p

PubChem (2021) Compound summary: Favipiravir. Available at: https://pubchem.ncbi.nlm.nih.gov/compound/Favipiravir. Accessed 01 July 2021 
Ramiro PN, Paula DM, da Gabriela Nascimento S, Mara Heloisa Neves OS (2021) A critical review on environmental presence of pharmaceutical drugs tested for the covid-19 treatment. Process Saf Environ Prot 152:568-582. https://doi.org/10.1016/j.psep.2021. 06.040

Rath S, Pereira LA, Bosco SMD, Maniero MG, Fostier AH, Guimarães JR (2016) Fate of ivermectin in the terrestrial and aquatic environment: mobility, degradation, and toxicity towards Daphnia similis. Environ Sci Pollut Res 23:5654-5666. https://doi.org/ 10.1007/s11356-015-5787-6

Reinstadler V, Ausweger V, Grabher A-L, Kreidl M, Huber S, Grander $\mathrm{J}$ et al (2021) Monitoring drug consumption in Innsbruck during coronavirus disease 2019 (COVID-19) lockdown by wastewater analysis. Sci Total Environ 757:144006. https://doi.org/10. 1016/j.scitotenv.2020.144006

Rendal C, Kusk KO, Trapp S (2011) The effect of pH on the uptake and toxicity of the bivalent weak base chloroquine tested on Salix viminalis and Daphnia magna. Environ Toxicol Chem 30:354359. https://doi.org/10.1002/etc.391

Revilla Pacheco C, Terán Hilares R, Colina Andrade G, MogrovejoValdivia A, AlfredoPacheco Tanaka D (2021) Emerging contaminants, SARS-COV-2 and wastewater treatment plants, new challenges to confront: a short review. Bioresour Technol Rep 15:100731. https://doi.org/10.1016/j.biteb.2021.100731

Roche (2020) Environmental risk assessment summary: Ribavirin. F. Hoffmann-La Roche Ltd, Group SHE (LSR), Available at: https://www.roche.com. Accessed 10 July 2021

Ryu T, Kim J, Kim K, Lee J, Kim J, Cho J, Yoon J, Lee J, Kim P, Ryu J (2018) Environmental risk assessment for ivermectin, praziquantel, Tamiflu and triclosan. Korean J Environ Health Sci 44:196-203. https://doi.org/10.5668/JEHS.2018.44.2.196

Sadio AJ, Gbeasor-Komlanvi FA, Konu RY, Bakoubayi AW, Tchankoni MK, Bitty-Anderson AM, Gomez IM, Denadou CP, Anani J, Kouanfack HR, Kpeto IK, Salou M, Ekouevi DK (2021) Assessment of self-medication practices in the context of the COVID19 outbreak in Togo. BMC Public Health 21:58. https://doi.org/ 10.1186/s12889-020-10145-1

Sanderson H, Laird B, Pope L, Brain R, Wilson C, Johnson D, Bryning G, Peregrine AS, Boxall A, Solomon K (2007) Assessment of the environmental fate and effects of ivermectin in aquatic mesocosms. Aquat Toxicol 85:229-240. https://doi.org/10.1016/j. aquatox.2007.08.011

Sanganyado E, Gwenzi W (2019) Antibiotic resistance in drinking water systems: occurrence, removal, and human health risks. Sci Total Environ 669:785-797. https://doi.org/10.1016/j.scitotenv. 2019.03.162

Sanganyado E, Lu Z, Fu Q, Schlenk D, Gan J (2017) Chiral pharmaceuticals: a review on their environmental occurrence and fate processes. Water Res 124:527-542. https://doi.org/10.1016/j. watres.2017.08.003

Sanganyado E, Lu Z, Liu W (2020) Application of enantiomeric fractions in environmental forensics: uncertainties and inconsistencies. Environ Res 184:109354. https://doi.org/10.1016/j.envres. 2020.109354

Satarker S, Ahuja T, Banerjee M, Vignesh Balaji E, Dogra S, Agarwal T, Nampoothiri M (2020) Hydroxychloroquine in COVID19: potential mechanism of action against SARS-CoV-2. Curr Pharmacol Rep 6:203-211. https://doi.org/10.1007/ s40495-020-00231-8

Scheurer M, Sacher F, Brauch HJ (2009) Occurrence of the antidiabetic drug metformin in sewage and surface waters in Germany. $\mathrm{J}$ Environ Monit 11:1608-1613. https://doi.org/10.1039/b909311g

Scheurer M, Michel A, Brauch HJ, Ruck W, Sacher F (2012) Occurrence and fate of the antidiabetic drug metformin and its metabolite guanylurea in the environment and during drinking water treatment. Water Res 46:4790-4802. https://doi.org/10.1016/j. watres.2012.06.019

Schroeder RL, Gerber JP (2014) Chloroquine and hydroxychloroquine binding to melanin: some possible consequences for pathologies. Toxicol Rep 1:963-968. https://doi.org/10.1016/j.toxrep. 2014.10.019

Schwientek M, Guillet G, Rügner H, Kuch B, Grathwohl P (2016) A high-precision sampling scheme to assess persistence and transport characteristics of micropollutants in rivers. Sci Total Environ 540:444-454

Slater FR, Singer AC, Turner S, Barr JJ, Bond PL (2011) Pandemic pharmaceutical dosing effects on wastewater treatment: no adaptation of activated sludge bacteria to degrade the antiviral drug Oseltamivir (Tamiflu ${ }^{\circledR}$ ) and loss of nutrient removal performance. FEMS Microbiol Lett 315:17-22. https://doi.org/10. 1111/j.1574-6968.2010.02163.x

Sternberg A, McKee DL, Naujokat C (2020) Novel drugs targeting the SARS-CoV-2/COVID-19 machinery. Curr Top Med Chem 20:1423-1433. https://doi.org/10.2174/15680266209992005170 43137

Straub JO (2009) An environmental risk assessment for oseltamivir $\left(\right.$ Tamiflu $\left.^{\circledR}\right)$ for sewage works and surface waters under seasonalinfluenza- and pandemic-use conditions. Ecotoxicol Environ Saf 72(6):1625-1634. https://doi.org/10.1016/j.ecoenv.2008.09.011

Sulaiman S, Khamis M, Nir S, Lelario F, Scrano L, Bufo SA, Karaman R (2015) Stability and removal of spironolactone from wastewater. J Environ Sci Health Part A Toxic Hazard Subst Environ Eng 50:1127-1135. https://doi.org/10.1080/10934529.2015.1047668

Sun H, He F, Choi W (2020) Production of reactive oxygen species by the reaction of periodate and hydroxylamine for rapid removal of organic pollutants and waterborne. Environ Sci Technol 54:6427-6437

Tarazona JV, Martínez M, Martínez MA, Anadón A (2021) Environmental impact assessment of COVID-19 therapeutic solutions. A prospective analysis. Sci Total Environ 778:146257

Tong L, Eichhorn P, Pérez S, Wang Y, Barceló D (2011) Photodegradation of azithromycin in various aqueous systems under simulated and natural solar radiation: kinetics and identification of photoproducts. Chemosphere 83:340-348. https://doi.org/10.1016/j. chemosphere.2010.12.025

Trawiński J, Skibiński R (2017) Studies on photodegradation process of psychotropic drugs: a review. Environ Sci Pollut Res 24:1152 1199. https://doi.org/10.1007/s11356-016-7727-5

Vaduganathan M, van Meijgaard J, Mehra MR, Joseph J, O'Donnell CJ, Warraich HJ (2020) Prescription fill patterns for commonly used drugs during the COVID-19 pandemic in the United States. JAMA 323:2524-2526. https://doi.org/10.1001/jama.2020.9184

Vambol S, Vambol V, Mozaffari N, Mahmoud AED, Ramsawak N, Mozaffari N, Ziarati P, Khan NA (2021) Comprehensive insights into sources of pharmaceutical wastewater in the biotic systems. Pharmaceut Wastew Treatment Technol. https://doi.org/10.2166/ 9781789061338

Vermillion Maier ML, Tjeerdema RS (2018) Azithromycin sorption and biodegradation in a simulated California river system. Chemosphere 190:471-480. https://doi.org/10.1016/j.chemosphere. 2017.10.008

Wang N, Shi X, Jiang L, Zhang S, Wang D, Tong P et al (2013) Structure of MERS-CoV spike receptor-binding domain complexed with human receptor DPP4. Cell Res 23(8):986. https://doi.org/ 10.1038/cr.2013.92

Wang Y, Lu J, Zhang S, Li J, Mao L, Yuan Z, Bond PL, Guo J (2021a) Non-antibiotic pharmaceuticals promote the transmission of multidrug resistance plasmids through intra- and intergenera conjugation. ISME J 15:2493-2508. https://doi.org/10.1038/ s41396-021-00945-7 
Wang J, Li S, Zhu Y, Guo J, Liu J, He B (2021b) Targeted eco-pharmacovigilance as an optimized management strategy for adverse effects of pharmaceuticals in the environment. Environ Toxicol Pharmacol 82:103565. https://doi.org/10.1016/j.etap.2020. 103565

Wenk J, Gunten Uv, Canonica S (2011) Effect of dissolved organic matter on the transformation of contaminants induced by excited triplet states and the hydroxyl radical. Environ Sci Technol 45:1334-1340. https://doi.org/10.1021/es102212t

WHO (World Health Organization) (2021a) https://covid19.who.int/ (WHO 2021a). Accessed 3 Oct 2021

WHO (World Health Organization) (2021b) https://covid19.who.int/ table (WHO 2021b)

Wu C, Chen X, Cai Y, Zhou X, Xu S, Huang H, Song Y (2020a) Risk factors associated with acute respiratory distress syndrome and death in patients with coronavirus disease 2019 pneumonia in Wuhan, China. JAMA Intern Med 180(7):934-943. https://doi. org/10.1001/jamainternmed.2020.0994

Wu R, Wang L, Kuo HC, Shannar A, Peter R, Chou PJ, Li S, Hudlikar R, Liu X, Liu Z, Poiani GJ (2020b) An update on current therapeutic drugs treating COVID-19. Curr Pharmacol Rep 6(3):56-70

Zhao Y, Kuang J, Zhang S, Li X, Wang B, Huang J, Deng S, Wang Y, Yu G (2017) Ozonation of indomethacin: kinetics, mechanisms and toxicity. J Hazard Mater 323:460-470. https://doi.org/10. 1016/j.jhazmat.2016.05.023

Zhong N, Zheng B, Li Y, Poon L, Xie Z, Chan K et al (2003) Epidemiology and cause of severe acute respiratory syndrome (SARS) in Guangdong, People's Republic of China, in February, 2003. Lancet 362(9393):1353-1358. https://doi.org/10.1016/s01406736(03)14630-2

Zurita JL, Jos Á, del Peso A, Salguero M, López-Artíguez M, Repetto $\mathrm{G}$ (2005) Ecotoxicological evaluation of the antimalarial drug chloroquine. Aquatic Toxicol 75(2):97-107

Publisher's Note Springer Nature remains neutral with regard to jurisdictional claims in published maps and institutional affiliations. 